\title{
Heat-Mitigation Effects of Irrigated Rice-Paddy Fields Under Changing Atmospheric Carbon Dioxide Based on a Coupled Atmosphere and Crop Energy-Balance Model
}

\author{
Hiroki Ikawa' (D) . Tsuneo Kuwagata ${ }^{1}$ (D) . Shigenori Haginoya ${ }^{1,3}$. \\ Yasushi Ishigooka $^{1} \cdot$ Keisuke Ono $^{1}$ (D) Atsushi Maruyama ${ }^{1}$ (D) - Hidemitsu Sakai ${ }^{1}$ (D) . \\ Minehiko Fukuoka $^{1} \cdot$ Mayumi Yoshimoto $^{1} \cdot$ Sachinobu Ishida $^{4}$ (D) Charles P. Chen ${ }^{5}$. \\ Toshihiro Hasegawa $^{6}$ (D) Tsutomu Watanabe ${ }^{2}$
}

Received: 16 May 2020 / Accepted: 8 January 2021 / Published online: 5 March 2021

(C) The Author(s) 2021

\begin{abstract}
Known as the heat-mitigation effect, irrigated rice-paddy fields distribute a large fraction of their received energy to the latent heat during the growing season. The present hypothesis is that increased atmospheric $\mathrm{CO}_{2}$ concentration decreases the stomatal conductance of rice plants and increases the air temperature by means of an increased sensible heat flux. To test this hypothesis, a coupled regional atmospheric and crop energy-balance model is developed and applied to a $300 \times 300 \mathrm{~km}^{2}$ region in Japan. Downscaling meteorological variables from grid-mean values of mixed land use $\left(3 \times 3 \mathrm{~km}^{2}\right)$ generates realistic typical diurnal cycles of air temperature in rice paddies and adjacent residential areas. The model simulation shows that, on a typical sunny day in summer, doubling the $\mathrm{CO}_{2}$ concentration increases the daily maximum grid-mean air temperature, particularly where rice paddies are present, by up to $0.7^{\circ} \mathrm{C}$. This $\mathrm{CO}_{2}$ effect on the grid-mean air temperature is approximately half the effect of the reduction in rice-paddy area that is postulated to occur on a time scale similar to that of the atmospheric $\mathrm{CO}_{2}$ change. However, within the internal atmospheric boundary layer of the rice paddies, the $\mathrm{CO}_{2}$ effect on the air temperature $\left(+0.44{ }^{\circ} \mathrm{C}\right)$ still exceeds the effects of the land-use change $\left(+0.11{ }^{\circ} \mathrm{C}\right)$. These results show a potentially important interplay of plant physiological responses regarding atmospheric $\mathrm{CO}_{2}$ in the heat-mitigation effect of rice-paddy fields under a changing climate.
\end{abstract}

Keywords Crop energy-balance model $\cdot$ Heat-mitigation effect $\cdot$ Regional atmospheric model $\cdot$ Rice-paddy field

Hiroki Ikawa

hirokiikawa@affrc.go.jp

Extended author information available on the last page of the article 


\section{Introduction}

The heat-mitigation effect of irrigated crop fields has been recognized for a long time (Holmes 1970). In response to ongoing climate changes, an interest has emerged regarding whether and how this effect enhances or mitigates environmental changes (Dong et al. 2016; Nocco et al. 2019; Du et al. 2019; Yang et al. 2020). In particular, rice paddies comprise the typical landscapes in many parts of eastern Asia, and their role in heat mitigation may be of interest.

Previous studies have reported that the vicinity of rice paddies is characterized by cooler air compared with the other surrounding land that does not have rice paddies (Oue et al. 1994; Wakiyama 2007; Dong et al. 2016; Kuwagata et al. 2018); this is because rice paddies distribute a large fraction of their received energy to latent heat (Oue 2005; Ikawa et al. 2017). Recent studies have reported that changing the areal extents of rice paddies affects the regional climate (e.g., Dong et al. 2016). However, to the best of our knowledge, no study has investigated how the heat-mitigation effect of rice paddies is altered by the physiological response of rice plants under a changing climate.

Increases in atmospheric carbon dioxide [hereinafter, this concentration in the background atmosphere is denoted as $\left[\mathrm{CO}_{2}\right]$ decrease the latent heat flux and increase the sensible heat flux via the stomatal closure of rice plants (Yoshimoto et al. 2005). Vegetation responses to increasing $\left[\mathrm{CO}_{2}\right]$ likely alter the energy balance and subsequently influence the state of the atmosphere, which in turn affects land-surface processes (VilàGuerau de Arellano et al. 2012, 2014). In an earlier study (Ikawa et al. 2018), we used a simple one-dimensional clear-sky atmospheric-boundary-layer (ABL) model to show that the air temperature and humidity in the atmosphere over a rice paddy are influenced by different $\left[\mathrm{CO}_{2}\right]$ and different cultivars. However, meteorological variables over lowland rice-paddy areas in Japan are also influenced by various other processes at different spatial and temporal scales, such as advection from the ocean (Kuwagata et al. 1994), thereby making it difficult to perform realistic simulations using a one-dimensional model. It is important to quantify temperature environments precisely based on a realistic diurnal variation for assessing the heat stress on rice grains because the susceptibility of crops to high temperature may vary throughout a day (Matsui and Hasegawa 2019).

We suggest that a combination of a regional atmospheric model and rice-crop energybalance model could realistically simulate the processes relevant to the heat-mitigation effects of rice paddies on different spatial scales. The regional atmospheric model would simulate the spatial variations of air temperature due to different land use and topography (Watanabe and Shimoyama 2015), whereas the crop energy-balance model would simulate ecophysiological responses to an in situ environment (Maruyama and Kuwagata 2010; Ikawa et al. 2018). While community models such as the Weather Research and Forecasting model (e.g., Liu et al. 2016) may also be useful tools, the heat-mitigation effect would be specific to crop species (Chen et al. 2018), and we are interested in quantifying the effects of ecophysiological processes that occur in rice paddies on $\mathrm{ABL}$ conditions.

The present study addresses the following specific research questions: (1) To what extent do the stomatal responses of rice plants to different levels of $\left[\mathrm{CO}_{2}\right]$ affect the air temperature of rice-paddy areas in Japan? (2) How is the change in air temperature due to the stomatal response compared with the impact of land-use change? The objectives corresponding to these questions are (i) to couple a regional atmospheric model and a 
rice-crop energy-balance model and simulate the air temperature at different levels of $\left[\mathrm{CO}_{2}\right]$, and (ii) to run the model with different areal fractions of rice paddies under current $\left[\mathrm{CO}_{2}\right]$ and compare the results with those obtained in objective (i).

\section{Methodology}

The rice-crop energy model is coupled with the atmospheric model as follows: the atmospheric model uses the surface fluxes estimated by the rice-crop energy-balance model for the rice paddies, and the crop energy-balance model uses the meteorological variables estimated by the atmospheric model. Each model is described below.

\subsection{Regional Atmospheric Model}

A hydrostatic mesoscale atmospheric model with the Boussinesq approximation is used to simulate the flow and scalar transport within the ABL. The model is based on that of Kimura and Arakawa (1983) but modified to allow air density to change vertically (Watanabe and Shimoyama 2015). The simulation domain is assumed to be static with no geostrophic force; the other settings are listed in Table 1. Using Einstein's summation notation $\left(i, j=1,2\right.$, and 3 unless stated otherwise), we define $x_{i}$ as a longitudinal coordinate ( $x$, positive towards the east), a lateral coordinate ( $y$, positive towards the north), and a terrainfollowing height $\left(z_{*}\right)$, respectively. The basic equations are the continuity equation and the equations of motion. All variables are Reynolds averaged unless otherwise noted.

The continuity equation is

Table 1 Model settings for the regional atmospheric model

\begin{tabular}{llll}
\hline Model parameter & $\begin{array}{l}\text { Symbol (if used in } \\
\text { the text) }\end{array}$ & Unit & Value \\
\hline Simulation date & - & - & $1-2$ August \\
Location & - & degree & $\begin{array}{c}34.5-37.5^{\circ} \mathrm{N}, \\
137.5-\end{array}$ \\
& & & $140.5^{\circ} \mathrm{E}$ \\
Horizontal grid size & $d x, d y$ & $\mathrm{~m}$ & 3000 \\
The number of grids $\left(x, y, z_{*}\right)$ & - & - & $89,111,50$ \\
The centre of the lowest vertical grid & $z_{* 1}$ & $\mathrm{~m}$ & $15.5^{*}$ \\
Height of the atmosphere top (grid bottom) & $z_{T O P}$ & $6000^{*}$ \\
Time integration of the atmospheric model & - & $\mathrm{m}$ & 30 \\
Time integration of the crop energy-balance model & - & $\mathrm{s}$ & 60 \\
Average $\theta$ of the calculation domain & $\Theta$ & $\mathrm{K}$ & 313.15 \\
Initial relative humidity at the sea level & - & $\%$ & 70 \\
Vertical increase of $\theta$ (initial) & - & $\mathrm{K} \mathrm{m}{ }^{-1}$ & 0.005 \\
Initial longitudinal and lateral velocity components & $u, v$ & $\mathrm{~m} \mathrm{~s}{ }^{-1}$ & 0 \\
\hline
\end{tabular}

*Values at the sea level 


$$
\frac{\partial h \rho_{0} u_{i}}{\partial x_{i}}=0
$$

where $h$ is the vertical distance between the atmosphere top ( $z_{\mathrm{TOP}}$, defined at $\left.6 \mathrm{~km}\right)$ and the terrain height $\left(z_{G}\right)$, and $\rho_{0}\left(\mathrm{~kg} \mathrm{~m}^{-3}\right)$ is the time-mean air density and is assumed to be dependent on height only. The velocity components $u_{1}, u_{2}$, and $u_{3}$ are the longitudinal $(u)$, lateral $(v)$, and vertical $\left(w_{*}\right)$ components, respectively. The longitudinal and lateral components $(i=1,2)$ are governed by

$$
\rho_{0} \frac{\partial h u_{i}}{\partial t}+\frac{\partial h \rho_{0} u_{i} u_{j}}{\partial x_{j}}=\varepsilon_{i j 3} h \rho_{0} f_{c} u_{j}-h \rho_{0} c_{p} \Theta \frac{\partial \pi^{\prime}}{\partial x_{i}}+g h \rho_{0} \frac{\theta^{\prime}}{\Theta} \frac{z_{T O P}-z_{*}}{z_{T O P}} \frac{\partial z_{G}}{\partial x_{i}}+\frac{z_{T O P}^{2}}{h} \frac{\partial}{\partial z_{*}}\left(\rho_{0} K_{M} \frac{\partial u_{i}}{\partial z_{*}}\right),
$$

where $t$ is time, $\varepsilon_{i j 3}$ is the alternating unit tensor, $f_{c}$ is the Coriolis parameter $\left(\mathrm{s}^{-1}\right), c_{p}$ $\left(\mathrm{J} \mathrm{kg}^{-1} \mathrm{~K}^{-1}\right)$ is the specific heat of dry air at constant pressure, $\Theta(\mathrm{K})$ is the reference potential air temperature of the calculation domain, $\pi^{\prime}$ is the spatial departure of the Exner function ( $\pi=T \Theta^{-1}$, where we define $T$ as the grid-mean air temperature) from its reference $\Pi$, which varies with height only $\left(\mathrm{d} \Pi / \mathrm{d} z=-g\left[c_{p} \Theta\right]^{-1}\right), g\left(\mathrm{~m} \mathrm{~s}^{-2}\right)$ is the acceleration due to gravity, $\theta^{\prime}(\mathrm{K})$ is the spatial departure of the potential air temperature from $\Theta$, and $K_{M}\left(\mathrm{~m}^{2} \mathrm{~s}^{-1}\right)$ is the vertical eddy viscosity obtained from a level-2 turbulence-closure model (Mellor and Yamada 1974, 1982). The turbulence-closure model is also used to evaluate the vertical eddy diffusivity $K_{H}\left(\mathrm{~m}^{2} \mathrm{~s}^{-1}\right)$ for scalars, as used in Eq. 4 . The advection terms are approximated by a third-order finite-difference scheme, and a sixth-order horizontal filter is applied to reduce shortwave numerical oscillations.

Using the hydrostatic assumption, the vertical velocity component $\left(u_{3}=w_{*}\right)$ is diagnosed from the continuity equation (Eq. 1), and the Exner function is calculated from the hydrostatic equation

$$
\frac{\partial \pi^{\prime}}{\partial z_{*}}=\frac{h}{z_{T O P}} \frac{g \theta^{\prime}}{c_{p} \Theta^{2}}
$$

with $\pi^{\prime}=0$ at the top boundary. Note that if $c_{p}$ is assumed to be spatially constant, then it does not need to be specified because it is cancelled upon being substituted into the first term on the right-hand side of Eq. 2. Finally, the equation governing a scalar $\chi$ [the gridmean potential air temperature $\theta(\mathrm{K})$, specific humidity $q\left(\mathrm{~g} \mathrm{~kg}^{-1}\right)$, and $\mathrm{CO}_{2}$ mixing ratio $\left.\left(\mathrm{g} \mathrm{kg}^{-1}\right)\right]$ transport is

$$
\rho_{0} \frac{\partial h \chi}{\partial t}+\frac{\partial h \rho_{0} \chi u_{j}}{\partial x_{j}}=\frac{z_{T O P}^{2}}{h} \frac{\partial}{\partial z_{*}}\left(\rho_{0} K_{H} \frac{\partial \chi}{\partial z_{*}}\right) .
$$

The $\mathrm{CO}_{2}$ mixing ratio is converted to atmospheric $\mathrm{CO}_{2}$ concentration, $C\left(\mu \mathrm{mol} \mathrm{mol}{ }^{-1}\right)$, using the molar mass of $\mathrm{CO}_{2}$ and dry air.

\subsection{Land-Surface Model}

The subgrid parametrization for energy fluxes over mixed land surfaces is realized using the area-weighted average of the fluxes calculated for six land types (rice paddy, city, other crops, grass, forest, and water surface) within a single grid (Fig. 1). Unlike a parametrization for a bulk land surface, the present method allows the use of parameters determined specifically for 


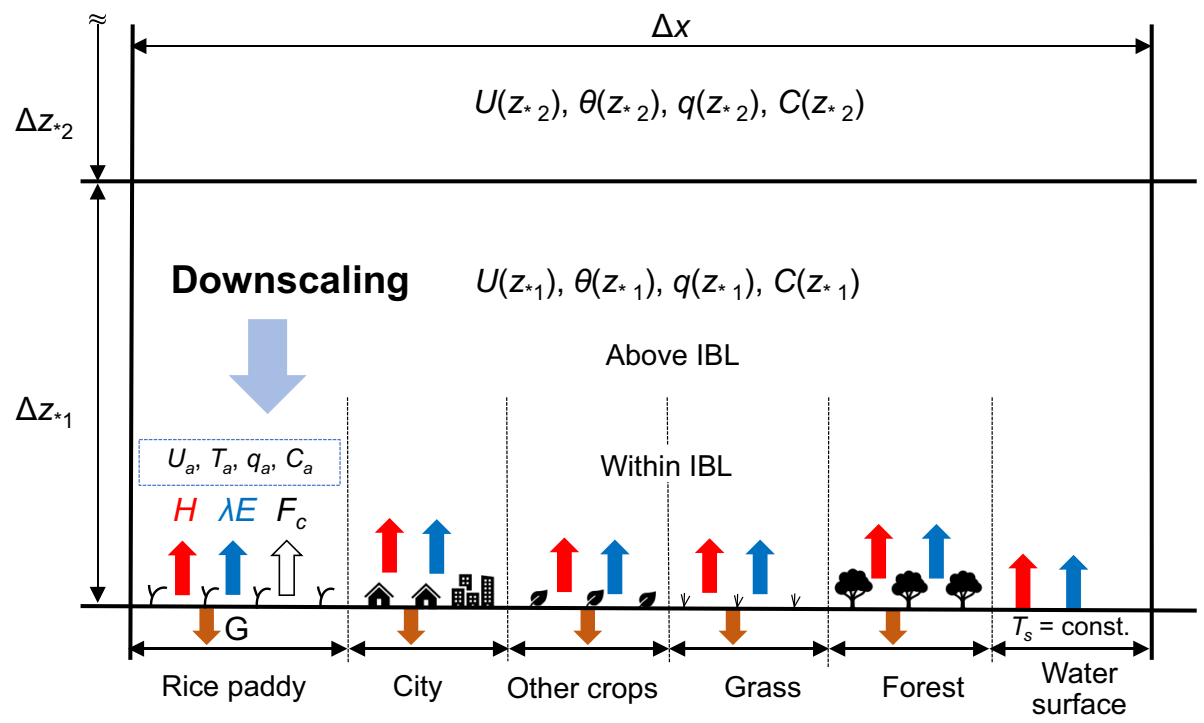

Fig. 1 Mixed land surfaces are aggregated within each surface grid of the regional atmospheric model following the procedure of Kimura (1989), after which downscaling of the meteorological variables within the internal boundary layer (IBL) is performed. The sensible heat flux $(H)$ and latent heat flux $(\lambda E)$ from each land-use category are aggregated based on their areal fraction and used as the boundary condition of the atmospheric model. The $\mathrm{CO}_{2}$ flux $\left(F_{c}\right)$ is assigned only for rice paddies in this study. The ground heat flux $(G)$ and surface temperature $\left(T_{s}\right)$ are determined for each land-use category for each surface grid. The wind speed $(U)$, potential air temperature $(\theta)$, specific humidity $(q)$, and atmospheric $\mathrm{CO}_{2}$ concentration $(C)$ within each grid are assumed to represent the aggregated land surface, and these meteorological variables within the IBL over each land-use category (denoted by the subscript ' $a$ ') are calculated during postprocessing

each land-use category (Kimura 1989; Avissar and Pielke 1989). Downscaling to estimate the meteorological variables within the internal boundary layer (IBL) over each land-use category is performed by means of postprocessing, as explained in Sect. 2.5.

\subsubsection{Rice-Crop Energy-Balance Model}

The rice-crop energy-balance model is based on the model of Ikawa et al. (2018), which comprises an energy-balance submodel (Watanabe 1994; Maruyama and Kuwagata 2010; Maruyama et al. 2017) and a canopy-photosynthesis submodel (de Pury and Farquhar 1997). The energy fluxes are calculated based on a so-called double-source model. For example, the latent heat flux $\lambda E\left(\mathrm{~W} \mathrm{~m}^{-2}\right)$ is the sum of the latent heat fluxes from the canopy $\left(\lambda E_{c}\right)$ and ground $\left(\lambda E_{g}\right)$ as follows

$$
\begin{gathered}
\lambda E=\lambda E_{c}+\lambda E_{g}, \\
\lambda E_{c}=\lambda \rho_{0}\left(z_{* 1}\right) C_{E c} U\left(z_{* 1}\right)\left[q_{\mathrm{sat}}\left(T_{c}\right)-q\left(z_{* 1}\right)\right], \\
\lambda E_{g}=\lambda \rho_{0}\left(z_{* 1}\right) C_{E g} U\left(z_{* 1}\right)\left[q_{\mathrm{sat}}\left(T_{g}\right)-q\left(z_{* 1}\right)\right],
\end{gathered}
$$




$$
C_{E c}=f\left(g_{s w}\right),
$$

where $\lambda\left(\mathrm{J} \mathrm{kg}^{-1}\right)$ is the latent heat of vaporization, $z_{* 1}$ is the height at the centre of the lowest grid layer of the atmospheric model $(\approx 15.5 \mathrm{~m}), U\left(\mathrm{~m} \mathrm{~s}^{-1}\right)$ is the wind speed, $T_{c}\left({ }^{\circ} \mathrm{C}\right)$ is the canopy temperature, $T_{g}\left({ }^{\circ} \mathrm{C}\right)$ is the ground temperature, and $C_{E c}$ and $C_{E g}$ are the vapour transfer coefficients for the canopy and the ground, respectively, the former being a function of the average stomatal conductance $g_{s w}\left(\mathrm{~mol} \mathrm{~m}^{-2} \mathrm{~s}^{-1}\right)$ for water vapour in the canopy. Note that herein we refer to $T_{c}$ as the effective aerodynamic temperature for sensible heat exchange. The sensible heat flux $H\left(\mathrm{~W} \mathrm{~m}^{-2}\right)$ is calculated in a similar manner and is set proportional to a product of the temperature gradient and the transfer coefficient.

Here, we approximate the average stomatal conductance, $g_{s w}$ by a parallel-resistance formula, which calculates the weighted mean value from $g_{s w}$ of sunlit $\left(g_{s w, \text { sun }}\right)$ and shaded $\left(g_{s w, \text { shd }}\right)$ leaves based on the photosynthesis and stomatal conductance submodel (FvCBL model) (Farquhar et al. 1980; Leuning 1995) as follows

$$
\begin{gathered}
g_{s w}=\frac{g_{s w, \text { sun }} L_{c, \text { sun }}+g_{s w, \text { shd }} L_{c, \text { shd }}}{L_{c}}, \\
g_{s w \text {,sun }}=f_{\mathrm{FvCBL}}\left(T_{c}, Q_{c, \text { sun }}, D_{c}, C_{a c}, v_{c_{\max } 25, \text { sun }}\right), \\
g_{s w \text {,shd }}=f_{\mathrm{FvCBL}}\left(T_{c}, Q_{c, \text { shd }}, D_{c}, C_{\mathrm{ac}}, v_{c_{\max } 25, \mathrm{shd}}\right),
\end{gathered}
$$

where $L_{c}$ is the leaf-area index (LAI), with $L_{c \text {,sun }}$ and $L_{c \text {,shd }}$ being the LAI for sunlit and shaded leaves, respectively, $Q_{c \text {,sun }}$ and $Q_{c \text {,shd }}\left(\mu \mathrm{mol} \mathrm{m}{ }^{-2} \mathrm{~s}^{-1}\right)$ are the absorbed photosynthetic photon flux densities by sunlit and shaded leaves, respectively, and $D_{c}(\mathrm{kPa})$ is the vapour pressure deficit between leaf and canopy air. The specific humidity and $\mathrm{CO}_{2}$ concentration in canopy $\left(C_{a c}\right)$ are approximated as $q$ and $C$ at the canopy top, respectively. Meteorological variables at the canopy top are estimated from those at height $z_{* 1}$ using Monin-Obukhov similarity theory as a first-order approximation.

The maximum carboxylation rates per leaf area at $25^{\circ} \mathrm{C}\left(\mu \mathrm{mol} \mathrm{m} \mathrm{m}^{-2}\right)$ for sunlit leaves $\left(v_{c_{\max } 25 \text {,sun }}\right)$ and shaded leaves $\left(v_{c_{\max } 25 \text {,shd }}\right)$ are calculated based on de Pury and Farquhar (1997), but modified using the leaf parameters for sunlit and shaded leaves for the FvCBL model (e.g., Sun et al. 2014; Masutomi et al. 2016), instead of using the bulk parameters for sunlit and shaded leaves, as follows

$$
\begin{gathered}
v_{c_{\max } 25 \text {,sun }}=\frac{\int_{0}^{L_{c}} \chi_{n}\left(N_{0}-N_{b}\right) \exp \left[-\left(k_{n}+k_{b}\right) L\right] \mathrm{d} L}{L_{c, \text { sun }}}=\frac{\chi_{n}\left(N_{0}-N_{b}\right)\left\{1-\exp \left[-\left(k_{n}+k_{b}\right) L_{c}\right]\right\}}{L_{c, \text { sun }}\left(k_{n}+k_{b}\right)}, \\
v_{c_{\max } 25, \text { shd }}=\frac{V_{c_{\max } 25}-v_{c_{\max } 25 \text {,sun }} L_{c, \text { sun }}}{L_{c, \text { shd }}}
\end{gathered}
$$

where $L$ is the cumulative leaf area from the canopy top, $\chi_{n}$ is a parameter for converting from leaf-nitrogen concentration to the maximum carboxylation rate, $N_{0}\left(\mathrm{mmol} \mathrm{m}^{-2}\right)$ is the specific leaf-nitrogen concentration at the canopy top, $N_{b}\left(\mathrm{mmol} \mathrm{m}^{-2}\right)$ is the specific leaf-nitrogen concentration not associated with carboxylation, $k_{n}$ is the coefficient of leafnitrogen allocation in the canopy, $k_{b}$ is the coefficient of beam-radiation extinction in the 
canopy, and $V_{\mathrm{cmax} 25}$ is the maximum carboxylation rate at $25^{\circ} \mathrm{C}$ for the whole canopy calculated as

$$
\begin{gathered}
V_{c_{\max } 25}=\int_{0}^{L_{c}} \chi_{n}\left(N_{0}-N_{b}\right) \exp \left(-k_{n} L\right) \mathrm{d} L \\
=\frac{\chi_{n}\left(N_{0}-N_{b}\right)\left[1-\exp \left(-k_{n} L_{c}\right)\right]}{k_{n}} .
\end{gathered}
$$

Note that the coefficient $k_{n}$ is defined differently using a factor of $L_{c}$ from the original model of de Pury and Farquhar (Hikosaka et al. 2016).

The stomatal conductance model based on Leuning (1995) is given as

$$
g_{s w}=\frac{m_{l} P_{n}}{\left(C_{s}-\Gamma\right)\left(1+\frac{D_{c}}{D_{0}}\right)}+g_{s w, \min },
$$

where $m_{l}$ is an empirical coefficient, $P_{n}\left(\mu \mathrm{mol} \mathrm{m}{ }^{-2} \mathrm{~s}^{-1}\right)$ is the net leaf photosynthesis, $C_{s}$ $\left(\mu \mathrm{mol} \mathrm{mol}{ }^{-1}\right)$ is the leaf surface $\mathrm{CO}_{2}$ concentration, $\Gamma\left(\mu \mathrm{mol} \mathrm{mol}{ }^{-1}\right)$ is the $\mathrm{CO}_{2}$ compensation point of $P_{n}, D_{0}$ is the reference vapour pressure deficit $(\mathrm{kPa})$, and $g_{s w, \min }\left(\mathrm{mol} \mathrm{m}^{-2} \mathrm{~s}^{-1}\right)$ is the minimum value of $g_{s w}$. We use values of $m_{l}, \Gamma, D_{0}$, and $g_{s w \text {,min }}$ following our earlier study (Ikawa et al. 2018).

The FvCBL model also requires the aerodynamic resistance of a leaf, which is calculated based on the leaf heat-exchange coefficient and wind speed within the canopy (Masutomi et al. 2016).

Most of the FvCBL parameters are based on leaf gas-exchange measurements for a common rice cultivar (Koshihikari) in the rice Free-Air $\mathrm{CO}_{2}$ Enrichment (FACE) experiment (Ikawa et al. 2018, 2019) (Table 2). The temperature function is also revised for photosynthesis parameters based on the $\mathrm{CO}_{2}$ concentration at the carboxylation site (Bernacchi et al. 2002). Accounting for mesophyll conductance may be preferable for accurately estimating photosynthesis under changing $\left[\mathrm{CO}_{2}\right]$ (Sun et al. 2014). For further details concerning the rice-crop energy-balance model, see Ikawa et al. (2018) and Maruyama and Kuwagata (2010).

\subsubsection{Energy-Flux Models for Other Land-Use Categories}

The bulk formulae based on Monin-Obukhov similarity theory for the surface stress $\tau$ $\left(\mathrm{kg} \mathrm{m}^{-1} \mathrm{~s}^{-2}\right)$ and surface fluxes of sensible heat and latent heat are used for the other land-use categories. Using the surface temperature $T_{s}$, the surface stress and energy fluxes are calculated as

$$
\begin{gathered}
\tau=\rho_{0}\left(z_{* 1}\right) C_{M} U\left(z_{* 1}\right)^{2}, \\
H=c_{p} \rho_{0}\left(z_{* 1}\right) C_{H} U\left(z_{* 1}\right)\left(T_{s}-T\left(z_{* 1}\right)\right), \\
\lambda E=\lambda \rho_{0}\left(z_{* 1}\right) C_{E} U\left(z_{* 1}\right)\left(q_{\mathrm{sat}}\left(T_{s}\right)-q\left(z_{* 1}\right)\right) .
\end{gathered}
$$




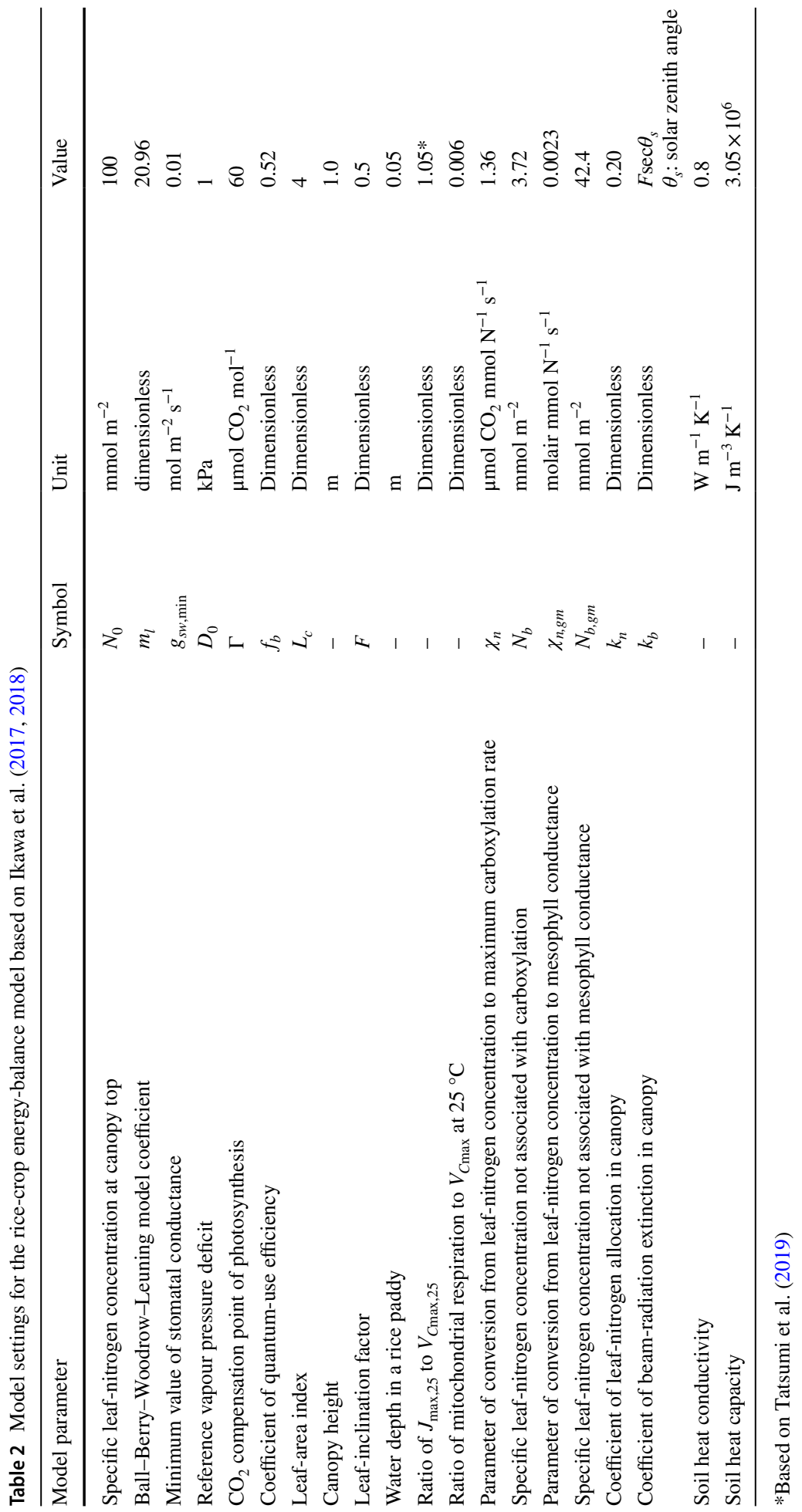


The transfer coefficient for each surface flux $\left(C_{M}, C_{H}\right.$, and $\left.C_{E}\right)$ is determined as

$$
\begin{gathered}
C_{M}=k^{2}\left[\ln \left(\frac{z_{1}-d}{z_{0}}\right)+\left.\Psi_{\mathrm{M}}\right|_{z_{0}} ^{z_{1}-d}\right]^{-2}, \\
C_{H}=k^{2}\left[\ln \left(\frac{z_{1}-d}{z_{0}}\right)+\left.\Psi_{\mathrm{M}}\right|_{z_{0}} ^{z_{1}-d}\right]^{-1}\left[\ln \left(\frac{z_{1}-d}{z_{T}}\right)+\left.\Psi_{\mathrm{H}}\right|_{z_{T}} ^{z_{1}-d}\right]^{-1}, \\
C_{E}=\beta C_{H},
\end{gathered}
$$

where $k$ is the von Kármán constant $(=0.4)$, and $\Psi_{\mathrm{M}}$ and $\Psi_{\mathrm{H}}$ are stability correction factors (dimensionless) (Dyer and Hicks 1970; Kondo et al. 1978). For each land-use category, the aerodynamic roughness length $z_{0}(\mathrm{~m})$, the thermal roughness length $z_{T}(\mathrm{~m})$, the zero-plane displacement $d(\mathrm{~m})$, the evaporation efficiency $\beta$ (dimensionless), the albedo (dimensionless), the soil heat capacity $\left(\mathrm{J} \mathrm{m}^{-3} \mathrm{~K}^{-1}\right)$, and the soil heat conductivity $\left(\mathrm{W} \mathrm{m}^{-1} \mathrm{~K}^{-1}\right.$ ) are set separately (Table 3$)$. The energy fluxes $(H$ and $\lambda E)$ are solved together with the heat-conduction equation of the soil. The temperature of the open water surface is left unchanged during the simulation.

\subsection{Model Simulation}

The model simulations are conducted for a specific study area (ca. $300 \times 300 \mathrm{~km}^{2}$ ) in Japan $\left(34.5-37.5^{\circ} \mathrm{N}, 137.5-140.5^{\circ} \mathrm{E}\right.$ ) (Fig. 2). The simulation domain is gridded by a $3 \times 3 \mathrm{~km}^{2}$ grid, and each square is categorized into the aforementioned land-use types based on the land-use map of 2006 obtained from the Geospatial Information Authority of Japan (GSI). Rice paddies account for $10 \%$ of the total land area, and $64 \%$ of all the grid squares has a non-zero areal fraction of rice paddies. Altitude data are also obtained from the GSI.

The weather and rice-growth conditions are taken as those on a typical summer day when rice fields are irrigated (water depth of $0.05 \mathrm{~m}$ ) and covered fully with leaves (LAI was set at $\left.4 \mathrm{~m}^{2} \mathrm{~m}^{-2}\right)$. The global shortwave flux $R_{s}\left(\mathrm{~W} \mathrm{~m}^{-2}\right)$ is determined based on extra terrestrial solar radiation, the solar zenith angle, and precipitable water to account for the effect of humidity on the attenuation (Kuwagata et al. 1990). The initial state of the potential temperature $\theta$ is set at $25{ }^{\circ} \mathrm{C}$ at the sea level and increases vertically at the rate of $0.005 \mathrm{~K} \mathrm{~m}^{-1}$. The wind speed is set to zero and the relative humidity is set to $70 \%$ at all vertical levels as the initial condition.

The top boundary conditions for wind speeds are set to zero. Radiation conditions are applied for the velocity components normal to the horizontal boundaries. Zero-gradient conditions are applied for scalars and velocity components parallel to the horizontal boundaries. Thus, the spatial variations of the velocity fields are induced by the thermally induced atmospheric circulation due to differences in energy balance and topography.

The simulations are run with a timestep of $30 \mathrm{~s}$ for the atmospheric model and $60 \mathrm{~s}$ for the rice energy-balance model. A spin-up simulation with a control condition is run for $20 \mathrm{~h}$ starting at 0700 local time $(\mathrm{LT}=\mathrm{UTC}+9 \mathrm{~h}$ ) to generate typical summer meteorological conditions in the area. Then, the following experimental simulations are run for $16 \mathrm{~h}$ (from 0300 to 1900 LT):

- Simulation 1 (Control) $\left[\mathrm{CO}_{2}\right]$ of $400 \mu \mathrm{mol} \mathrm{mol}^{-1}$. 


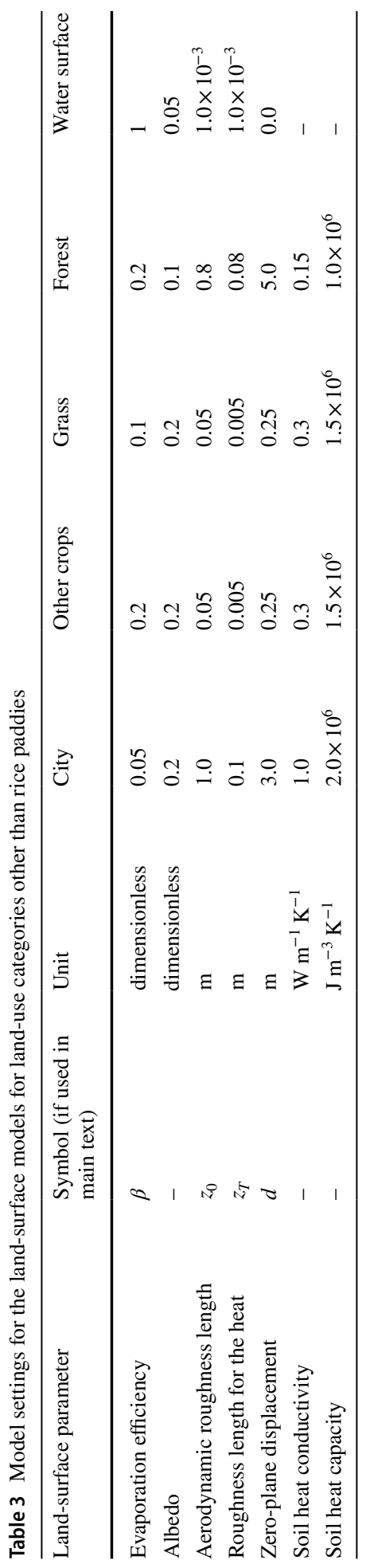



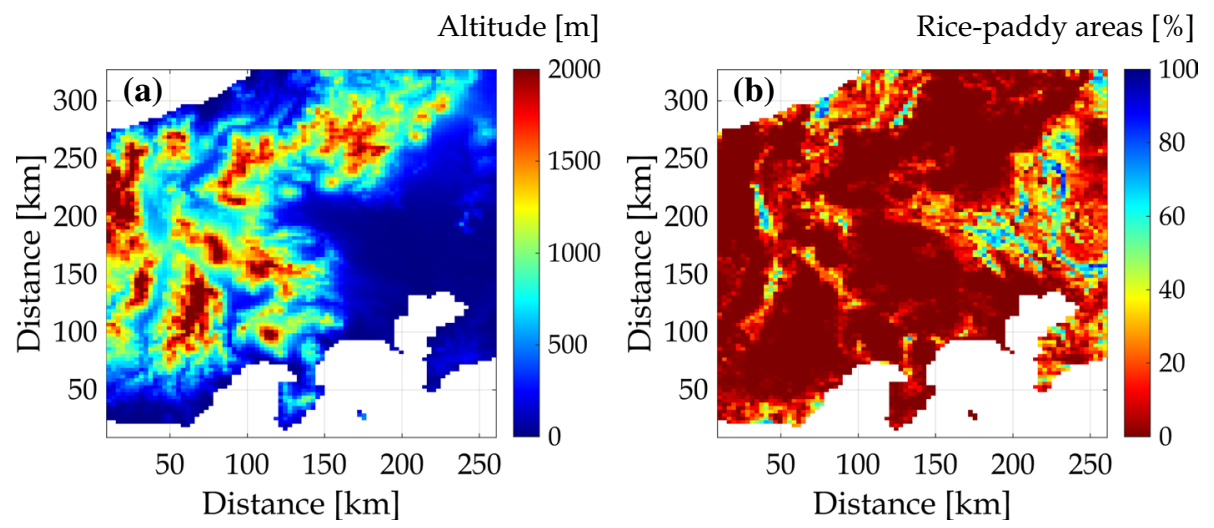

Fig. 2 Simulation domain in Japan $\left(34.5-37.5^{\circ} \mathrm{N}, 137.5-140.5^{\circ} \mathrm{E}\right)$ : a altitude; b areal percentage of rice paddies

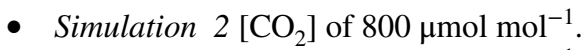

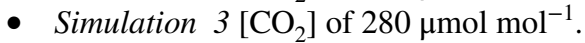

- Simulation 4 Increased rice-paddy area within each grid square by $20 \%$ from the control.

- Simulation 5 Decreased rice-paddy area within each grid square by $20 \%$ from the control.

We assume that the time period over which the rice-paddy areas change by $40 \%$ corresponds reasonably to that in which $\left[\mathrm{CO}_{2}\right]$ increases from 280 to $800 \mu \mathrm{mol} \mathrm{mol}^{-1}$ on a century scale. The changes in rice-paddy area are compensated by the area of city within each grid square, while the areas of the other land-use types remain unchanged in each of the five simulations.

The downwards radiation fluxes at the surface (the global shortwave flux $R_{s}$, the diffuse shortwave flux, and the longwave flux) are prescribed based on the initial state of the atmosphere; however, the present study do not consider the precise radiation transfer within the atmosphere and the feedback effects of the land surface on the radiation conditions (see Appendix 1). The photosynthetic photon flux density $\left(\mu \mathrm{mol} \mathrm{m} \mathrm{m}^{-2} \mathrm{~s}^{-1}\right.$ ) above the canopy is assumed to be proportional to $R_{s}\left(\mathrm{~W} \mathrm{~m}^{-2}\right)$ by a factor of 2 , and the distribution between the absorbed photosynthetic photon flux density, $Q_{c \text {,sun }}$ and $Q_{c \text {, shd }}$ is calculated following de Pury and Farquhar (1997). Atmospheric tendencies are not considered in this study.

\subsection{Heat-Budget Analysis of the Atmospheric Boundary Layer}

The heat budget of the atmosphere within the ABL is calculated (e.g., Kuwagata et al. 1990) from the beginning of the simulation (0300 LT) until 1300 LT when differences in simulated meteorological variables between different runs are pronounced. The aim of this analysis is to differentiate the effects of heating via the sensible heat flux at the 
surface $\left(Q_{H}\right)$ and heating via advection $\left(Q_{a d v}\right)$ on the net heating in the atmospheric column $\left(Q_{n}\right)$

$$
\begin{gathered}
Q_{n}=t_{\text {total }}^{-1} \int_{t=03 \mathrm{LT}}^{t=13 \mathrm{LT}} \int_{0}^{z_{* h}} \rho_{0} c_{p} \frac{h}{z_{T O P}} \frac{\partial \theta}{\partial t} \mathrm{~d} z_{*} \mathrm{~d} t, \\
Q_{H}=t_{\text {total }}^{-1} \int_{t=03 \mathrm{LT}}^{t=13 \mathrm{LT}} H \mathrm{~d} t, \\
Q_{a d v}=Q_{n}-Q_{H} .
\end{gathered}
$$

Herein, $t_{\text {total }}(\mathrm{s})$ is the total simulation duration $(10 \mathrm{~h})$ in seconds and $z_{* h}$ is the peak ABL height during the period of the heat-budget analysis. We set $z_{* h}$ at $2 \mathrm{~km}$ based on the simulation without the topographic effects (Online Supplement Fig. S1).

\subsection{Downscaling Meteorological Variables}

The simulated meteorological variables for the lowest grid layer represent the average atmospheric state over the mixture of different land-use categories in each surface grid square, regardless of the fact that there might be different meteorological variables within each IBL (Fig. 1). First, we define the grid-mean meteorological variables (i.e., $U, T$, $q$, and $C$ ) downscaled for the height of $z_{r}$ within the IBL for each land-use category as

$$
\begin{aligned}
& U_{a}=U\left(z_{r}\right), \\
& T_{a}=T\left(z_{r}\right), \\
& q_{a}=q\left(z_{r}\right), \\
& C_{a}=C\left(z_{r}\right) .
\end{aligned}
$$

The meteorological variables at $z_{r}$ (i.e., $U_{a}, T_{a}, q_{a}$, and $C_{a}$ ) are estimated from those at $z_{* 1}$ using Monin-Obukhov similarity theory (e.g., Garratt 1994). For example, the variables $U_{a}$ and $T_{a}$ are calculated as

$$
\begin{gathered}
U_{a}=U\left(z_{* 1}\right)+\frac{u_{*}}{k}\left[\ln \left(\frac{z_{r}-d}{z_{1}-d}\right)+\left.\Psi_{\mathrm{M}}\right|_{z_{1}-d} ^{z_{r}-d}\right], \\
u_{*}=\sqrt{\frac{\tau}{\rho_{0}\left(z_{* 1}\right)},} \\
T_{a}=T\left(z_{* 1}\right)+\frac{\theta_{*}}{k}\left[\ln \left(\frac{z_{r}-d}{z_{1}-d}\right)+\left.\Psi_{\mathrm{H}}\right|_{z_{1}-d} ^{z_{r}-d}\right],
\end{gathered}
$$




$$
\begin{gathered}
T\left(z_{* 1}\right)=\theta\left(z_{* 1}\right) \Pi\left(z_{* 1}\right)-273.15, \\
\theta_{*}=-\frac{H}{u_{*} c_{p} \rho_{0}\left(z_{* 1}\right)},
\end{gathered}
$$

We select $z_{r}$ to be $1.5 \mathrm{~m}$ above the zero-plane displacement assuming that the meteorological variables at the height $z_{r}$ represent the state of the specific land use on the subgrid scale of a few hundred metres.

\subsection{Evaluation of Model Performance}

The reason for using the regional atmospheric model rather than the slab model, which was used in our previous study (Ikawa et al. 2018), is to simulate the diurnal cycle of air temperature as realistically as possible over the complex terrain in Japan. We use hourly observed data of air temperature from a rice paddy $[(x, y)=(165 \mathrm{~km}, 185 \mathrm{~km})$ in Fig. 2] and from a residential area ('city') $[(x, y)=(167 \mathrm{~km}, 183 \mathrm{~km})]$ within the simulation domain (Kumagaya city) using the dataset of Kuwagata et al. (2014), and we compare those with the simulated air temperature $T_{a}$ averaged over the areas within $20 \mathrm{~km}$ from each site and at altitudes below $100 \mathrm{~m}$ (the number of grids, $n=119$ for rice and $n=122$ for city) under different conditions of downwards shortwave radiation at the surface, $R_{s}$. We choose the dataset of Kuwagata et al. (2014) because their study area comprises a typical landscape mixed with farm areas and adjacent cities in the Kanto plain, which accounts for a large fraction of the present study domain (ca. $x>150 \mathrm{~km}, y<250 \mathrm{~km}$ in Fig. 2). Note that while Kuwagata et al. (2014) reported daily and monthly data, they did not explicitly present the hourly data used here.

\section{Results}

\subsection{Comparison with Observations}

The diurnal patterns of air temperature $T_{a}$ in the control simulation and the simulation in which the $R_{s}$ values are reduced by $40 \%$ are similar to the observed air temperatures under similar meteorological conditions over both the rice-paddy and residential areas (Fig. 3). As the downwards radiation in the simulations is assigned typical summer values for this region, the diurnal variations in the value of $R_{s}$ do not agree perfectly between the observations and simulation results (Fig. 3b). Nevertheless, it can clearly be seen that the difference in air temperature between the two land-use types is greater under the higher $R_{s}$ values during the daytime $\left(R_{s}>0\right)$ both in the observations and simulation results. The greater difference in $T_{a}$ values during the periods of higher $R_{s}$ values is consistent with observations within and near the domain of the present study (Kuwagata et al. 2014, 2018). As we do not consider the urban canopies in our land-surface model, the simulated diurnal patterns of air temperature in the city areas may not be accurate (Kusaka et al. 2001; Kusaka and Kimura 2004). However, while the effect of urban canopies is generally pronounced at night, the present study focuses primarily on daytime air temperature. 

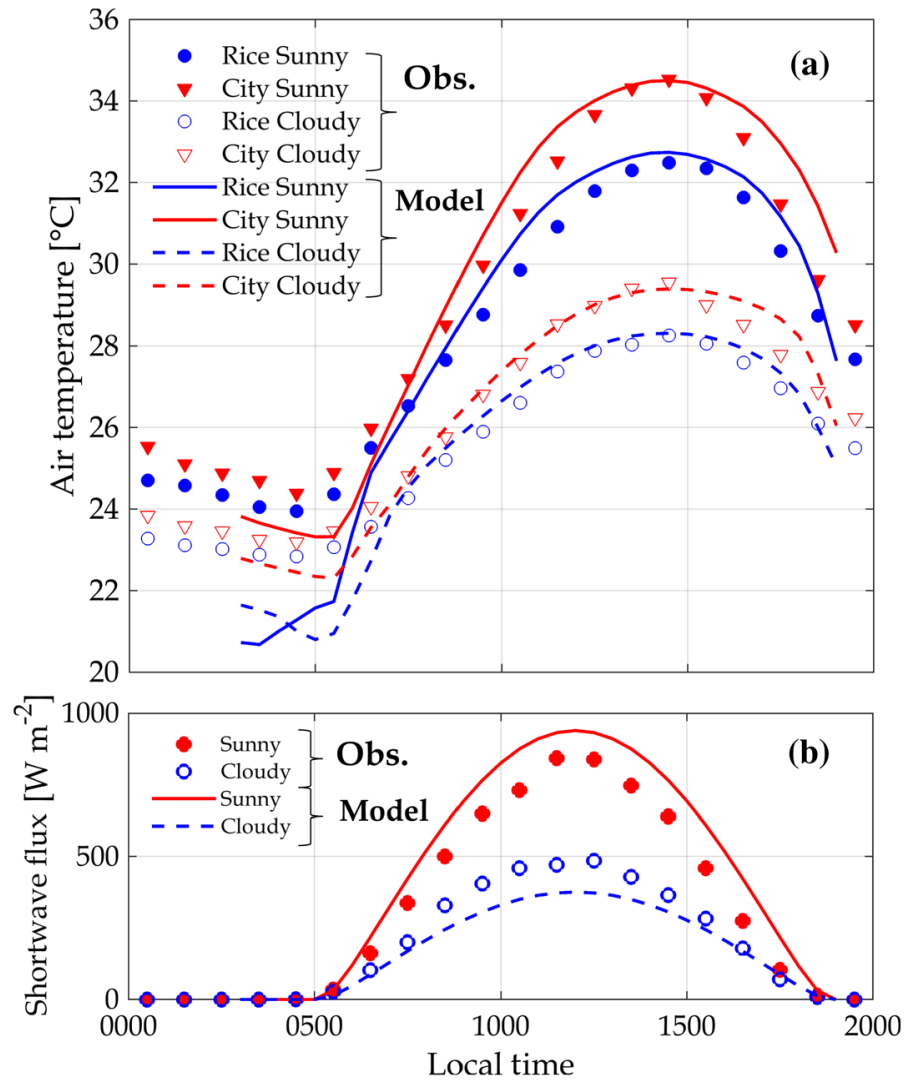

Fig. 3 Performance of model evaluated by comparing observed air temperature in rice-paddy and city areas in July-August 2012 (61 days) (Kuwagata et al. 2014, 'Obs.' in the legend) and simulated air temperature ( $T_{a}$ is the air temperature at $1.5 \mathrm{~m}$ above the zero-plane displacement) averaged over rice paddies $(n=119)$ and cities $(n=122)$ within $20 \mathrm{~km}$ of each site ('Model'): a comparisons by categorizing observed data into two sets with the daily maximum value of the global shortwave flux either higher (34 days, Sunny) or lower (27 days, Cloudy) than $800 \mathrm{~W} \mathrm{~m}^{-2}$; b control simulation and simulation with $40 \%$ of shortwave flux performed for sunny and cloudy days

\subsection{Near-Surface Air Temperature}

Figure $4 \mathrm{a}$ shows the simulated potential temperature $\theta\left(z_{* 1}\right)$ together with the relative sizes of the velocity vectors for the control simulations. The simulations are able to generate typical velocity fields that are strongly influenced by the sea breeze around the coastal areas (e.g., Kuwagata et al. 1994). It is evident that the value of $\theta\left(z_{* 1}\right)$ is greater in the area of Tokyo bay $[(x, y) \approx(200 \mathrm{~km}, 150 \mathrm{~km})]$ than in the adjacent areas northward where rice paddies are extended over large areas, even though these areas have similar topographies (Fig. 2a).

Doubling $\left[\mathrm{CO}_{2}\right]$ clearly increases the value of $\theta\left(z_{* 1}\right)$ in an extensive area of the simulation domain (Fig. 4b). At 1300 LT when the difference in potential temperature $\theta\left(z_{* 1}\right)$ among the simulations is greatest, the difference in $\theta\left(z_{* 1}\right)$ is almost $0.7^{\circ} \mathrm{C}$ in some areas. The temperature difference is particularly clear wherever rice paddies are aggregated, as shown in Fig. 2 b. 

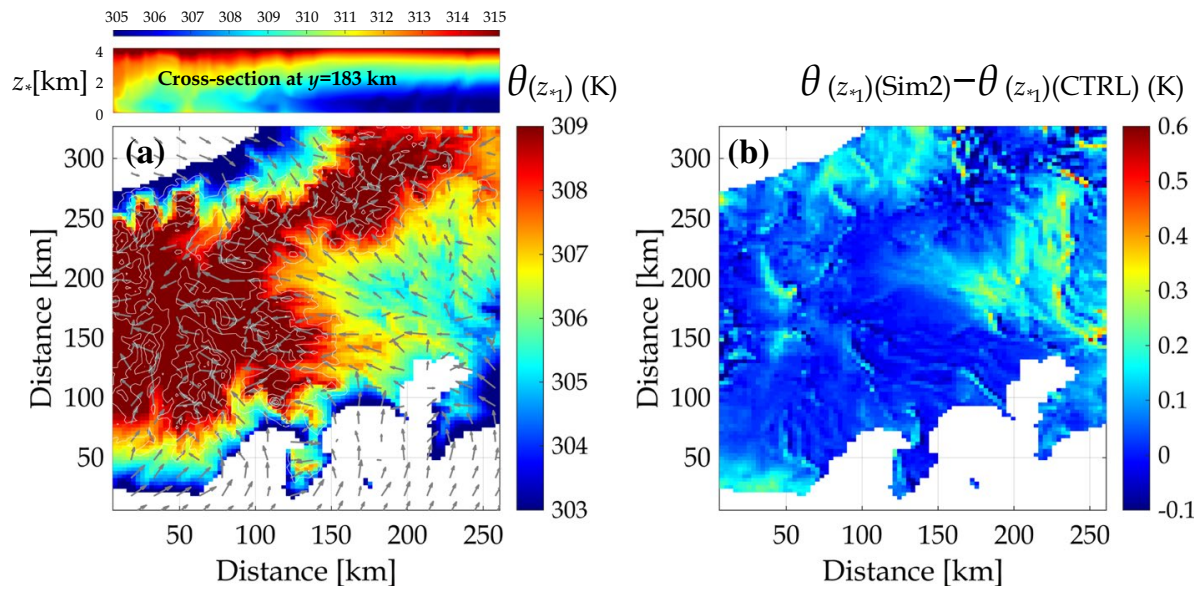

Fig. 4 a Simulated potential air temperature $\theta$ in the lowest grid layer $\left(z_{* 1}\right)(\approx 15.5 \mathrm{~m}$ above the surface at the centre of the grid) under control conditions (CTRL) at 1300 LT. The grey arrows are the relative velocity vectors and the contours indicate topography. $\mathbf{b}$ Increase in $\theta$ values in simulation 2 , in which the background atmospheric $\mathrm{CO}_{2}$ concentration is doubled from that in the control conditions
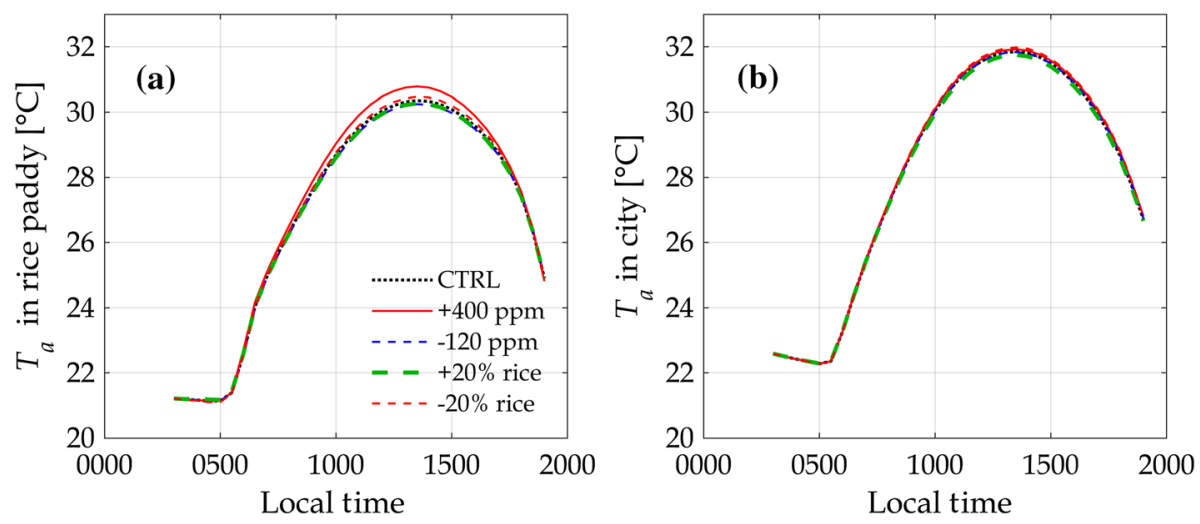

Fig. 5 Air temperature $1.5 \mathrm{~m}$ above the zero-plane displacement $\left(T_{a}\right)$ over a rice paddies and $\mathbf{b}$ cities under control conditions (CTRL), increased or decreased background atmospheric $\mathrm{CO}_{2}$ concentration $(+400$ or $\left.-120 \mu \mathrm{mol} \mathrm{mol}^{-1}\right)$, and increased or decreased rice-paddy areas $(+20 \%$ or $-20 \%)$. The data in both a, b are averaged from 4231 grid squares in which the areal fractions of city and rice paddy are non-zero

Both changing the areal fraction of rice paddies and changing $\left[\mathrm{CO}_{2}\right]$ clearly affects the simulated value of $T_{a}$ over rice paddies and cities (Fig. 5). We reason that the change in the value of $T_{a}$ in the simulations for the other land-use types reflects the changes in air temperature over a large spatial scale beyond the rice-paddy areas. We therefore choose to investigate the air temperature $T_{a}$ in cities and compare it with the case of rice paddies.

For rice paddies, the changing $\left[\mathrm{CO}_{2}\right]$ has a greater effect on $T_{a}$ than did the changing land use. Doubling $\left[\mathrm{CO}_{2}\right]$ increases the peak value of $T_{a}$ by $0.44{ }^{\circ} \mathrm{C} \pm 0.09{ }^{\circ} \mathrm{C}$, and the increased value of $T_{a}$ exceeds $0.7^{\circ} \mathrm{C}$ in some areas $(n=4231)$ (Figs. 5a and 6a). In contrast, 

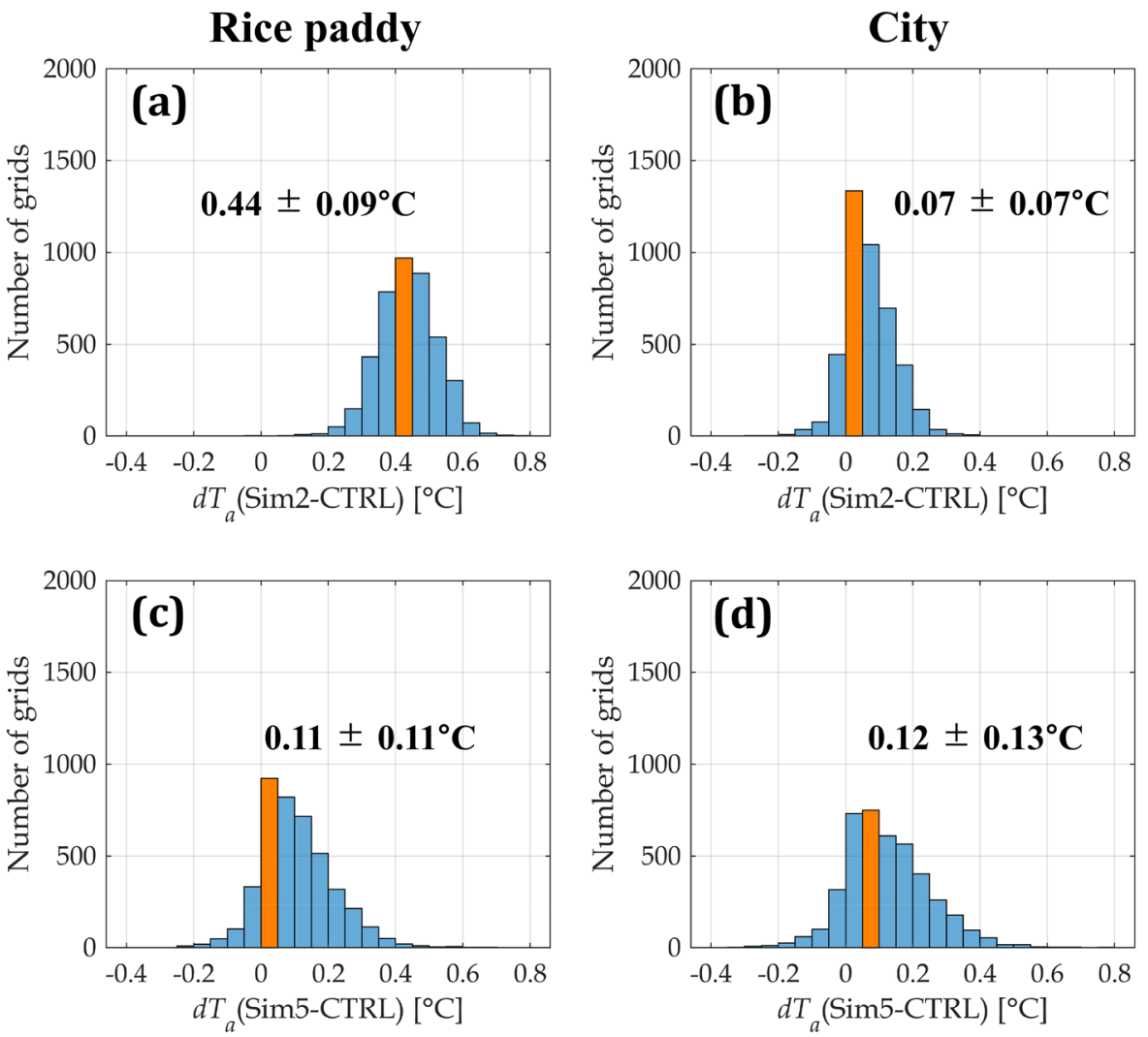

Fig. 6 Histograms of the air-temperature change $1.5 \mathrm{~m}$ above the zero-plane displacement $\left(d T_{a}\right)$ in simulation 2 (increased background atmospheric $\mathrm{CO}_{2}$ concentration by $400 \mu \mathrm{mol} \mathrm{mol}^{-1}$ ) compared with the control conditions (CTRL) (a, b) and in simulation 5 (decreased rice-paddy area by 20\%) compared with the control conditions $(\mathbf{c}, \mathbf{d})$ for rice paddies $(\mathbf{a}, \mathbf{c})$ and cities $(\mathbf{b}, \mathbf{d})$ at 1300 LT. The data are averaged from 4231 grid squares in which the areal fractions of city and rice paddy were non-zero. The numbers indicate the mean and standard deviation

decreasing rice-paddy areas by $20 \%$ increases the peak value of $T_{a}$ by $0.11{ }^{\circ} \mathrm{C} \pm 0.11{ }^{\circ} \mathrm{C}$ $(n=4231)$ (Figs. 5a and 6c). For cities, by contrast, the effect of land-use change on the air temperature $T_{a}$ is greater than the effect of changing $\left[\mathrm{CO}_{2}\right]$ (Fig. 5b). Doubling $\left[\mathrm{CO}_{2}\right]$ and reducing rice-paddy areas increases the peak value of $T_{a}$ over the cities by $0.07 \pm 0.07{ }^{\circ} \mathrm{C}$ and $0.12 \pm 0.13{ }^{\circ} \mathrm{C}$, respectively $(n=4231)$ (Figs. $5 \mathrm{~b}$ and $\left.6 \mathrm{~b}, \mathrm{~d}\right)$. The effects of land-use change on the value of $T_{a}$ are more spatially variable compared with those of the change in $\left[\mathrm{CO}_{2}\right]$ (Fig. 6), and some cities experience an increase in the value of $T_{a}$ of approximately $0.7{ }^{\circ} \mathrm{C}$ in response to decreasing rice-paddy areas (Fig. 6d). If both doubling $\left[\mathrm{CO}_{2}\right]$ and reducing rice-paddy areas were included, the peak value of $T_{a}$ of the rice paddies and cities would increase by $0.53 \pm 0.15^{\circ} \mathrm{C}$ and $0.18 \pm 0.16^{\circ} \mathrm{C}$, respectively (data not shown). 

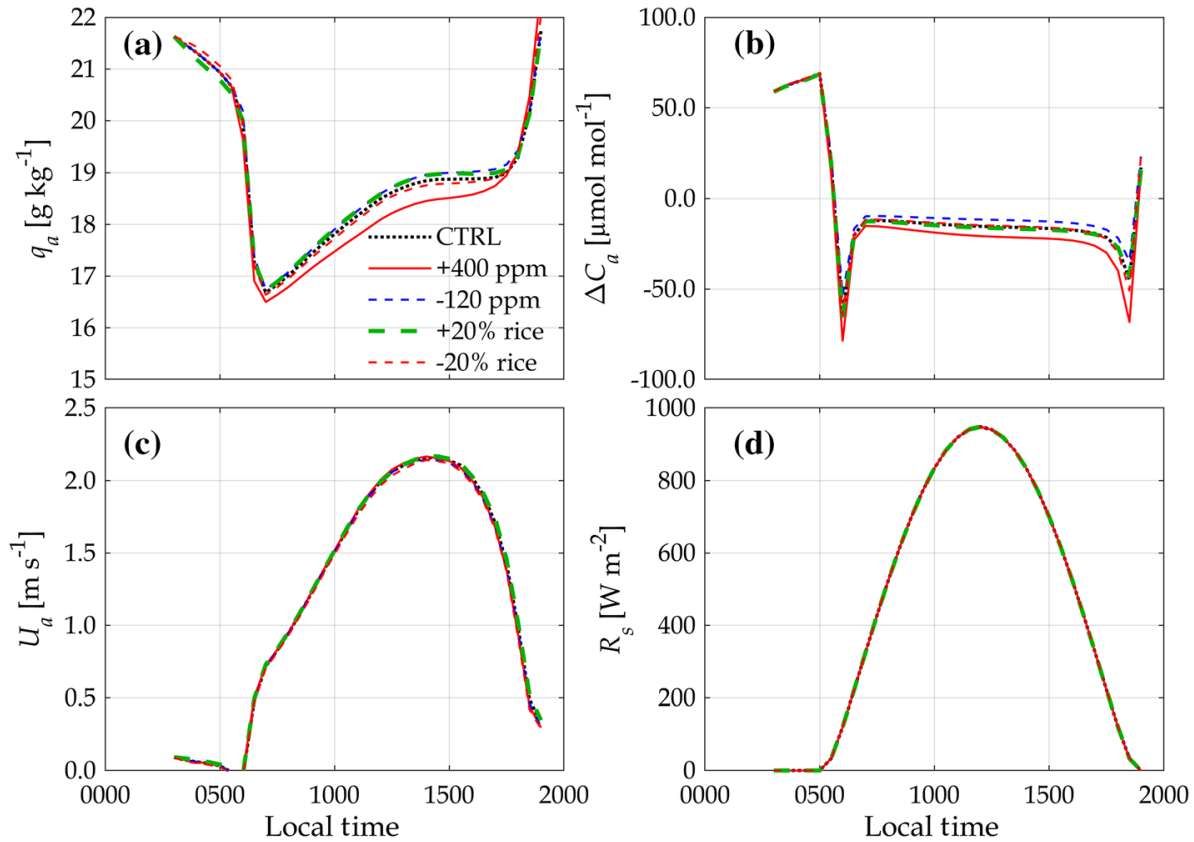

Fig. 7 Simulated meteorological variables over rice paddies (1.5 $\mathrm{m}$ above the zero-plane displacement): a specific humidity $\left(q_{a}\right)$, b anomaly of atmospheric $\mathrm{CO}_{2}$ concentration within the IBL from the background concentration $\left(\Delta C_{a}\right)$, $\mathbf{c}$ wind speed $\left(U_{a}\right)$, and $\mathbf{d}$ the global shortwave flux $\left(R_{s}\right)$. The simulations were performed under control conditions (CTRL), increased or decreased background atmospheric $\mathrm{CO}_{2}$ concentration $\left(+400\right.$ or $\left.-120 \mu \mathrm{mol} \mathrm{mol}^{-1}\right)$, and increased or decreased rice-paddy areas $(+20 \%$ or $-20 \%)$. The data are averaged from 4231 grids in which the areal fraction of rice paddy is non-zero

\subsection{Other Meteorological Variables and Energy Balance}

The directions of changes in the specific humidity, $q_{a}$ in the different simulations are opposite to those of the air temperature $T_{a}$ (Fig. 7a). Doubling $\left[\mathrm{CO}_{2}\right]$ decreases the magnitude of $q_{a}$ in the rice paddies by $0.40 \mathrm{~g} \mathrm{~kg}^{-1}$ at $1300 \mathrm{LT}$. Decreasing the rice-paddy area decreases the value of $q_{a}$, and increasing the rice-paddy area increases the value of $q_{a}$. Doubling $\left[\mathrm{CO}_{2}\right]$ decreases $\Delta C_{a}$ (the $C_{a}$ anomaly from $\left[\mathrm{CO}_{2}\right]$ ) (Fig. 7b). The differences in $\Delta C_{a}$ between the simulations are attributed to the differences in the canopy photosynthesis (Online Supplement Fig. S2). Similar to the air temperature $T_{a}$ in the rice paddies (Fig. 5a), the changes in $q_{a}$ and $\Delta C_{a}$ in the rice paddies are greater in response to $\left[\mathrm{CO}_{2}\right]$ changes than to land-use changes (Fig. 7a, b). Increasing the rice-paddy areas increases the wind speed $U_{a}$ and decreasing the rice-paddy areas decreases the value of $U_{a}$ because of the smaller roughness length of rice paddies compared with cities (Fig. 7c), but these changes are marginal. We held $R_{s}$ invariant between different simulations (Fig. 7d).

The differences in the values of $T_{a}$ and $q_{a}$ between the rice paddies and the cities in the simulations are attributed to the differences in the energy distribution of the fluxes $\lambda E$ and $H$. The grid-mean energy-balance components differ more in the simulations with different rice-paddy areas than in those with different $\left[\mathrm{CO}_{2}\right]$, whereas the energybalance components in the rice paddies are influenced more by different $\left[\mathrm{CO}_{2}\right]$ than by different areal fractions of rice paddies (Fig. 8). A clear change in the value of $H$ of 

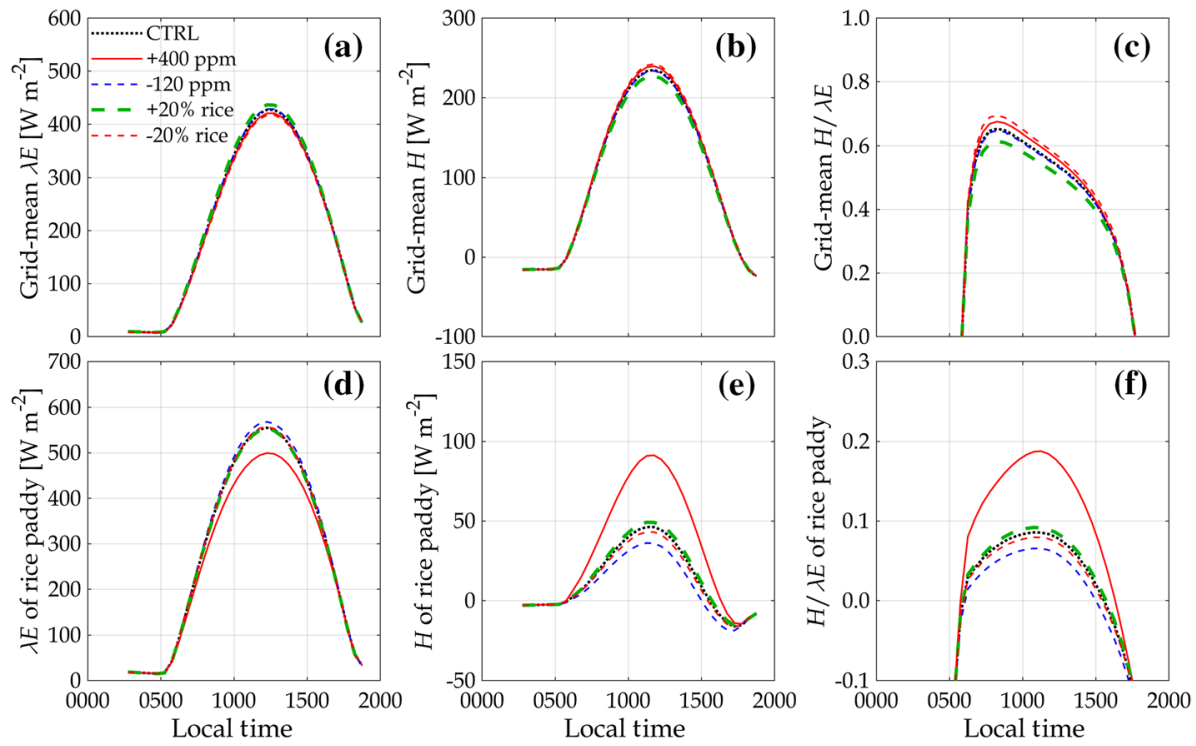

Fig. 8 Simulated energy-balance components: a grid-mean latent heat flux $(\lambda E)$, b grid-mean sensible heat flux $(H)$, c ratio of grid-mean $H$ and grid-mean $\lambda E$, d latent heat flux $(\lambda E)$ of rice paddies, e sensible heat flux $(H)$ of rice paddies, and $\mathbf{f}$ ratio of $H$ and $\lambda E$ in rice paddies. The simulations were performed under control conditions (CTRL), increased or decreased background atmospheric $\mathrm{CO}_{2}$ concentration $(+400$ or $\left.-120 \mu \mathrm{mol} \mathrm{mol}^{-1}\right)$, and increased or decreased rice-paddy areas $(+20 \%$ or $-20 \%)$. The data are averaged from 4231 grids in which the areal fraction of rice paddy is non-zero
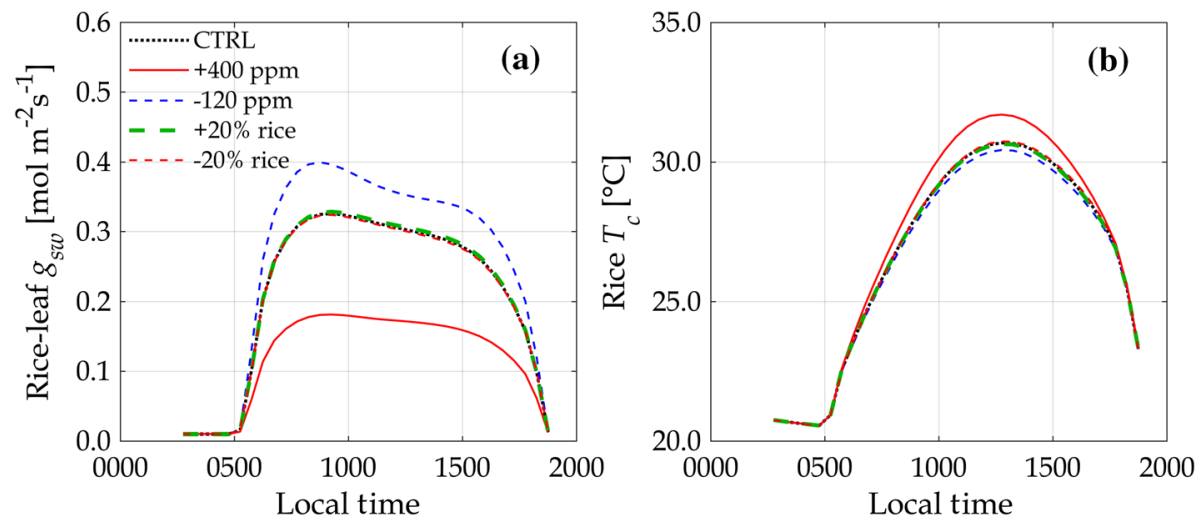

Fig. 9 a Stomatal conductance $\left(g_{s w}\right)$ of rice leaves and $\mathbf{b}$ canopy temperature $\left(T_{c}\right)$ obtained from the model simulations. The simulations were performed under control conditions (CTRL), increased or decreased background atmospheric $\mathrm{CO}_{2}$ concentration $\left(+400 \mathrm{or}-120 \mu \mathrm{mol} \mathrm{mol}{ }^{-1}\right.$ ), and increased or decreased ricepaddy areas $(+20 \%$ or $-20 \%)$. The data are averaged from 4231 grids in which the areal fraction of rice paddy is non-zero

the rice paddies is observed in the simulation with elevated $\left[\mathrm{CO}_{2}\right]$, with the value of $H$ increasing by up to $50 \mathrm{~W} \mathrm{~m}^{-2}$ (Fig. 8e). The changes in $\lambda E$ of the rice paddies between different simulations are attributed to different values of $g_{s w}$, but the differences in 
$\lambda E$ between the simulations are much smaller than that for $g_{s w}$ on a percentage basis (Figs. 8d and 9a). Differences in the effective aerodynamic temperature, $T_{c}$ between different $\left[\mathrm{CO}_{2}\right]$ simulations are greater than the differences in the air temperature $T_{a}$ (Fig. 9b). On average, the elevated $\left[\mathrm{CO}_{2}\right]$ increases $T_{c}$ by $1.0^{\circ} \mathrm{C}$ at $1300 \mathrm{LT}$. Slight differences in $g_{s w}$ between different rice-paddy areas and consequent small changes in the value of $T_{c}$ and energy fluxes are likely due to different meteorological conditions (i.e., $T_{a}$ and $q_{a}$ ), as shown in Figs. 5 and 7.

\subsection{Temperature, Humidity, and $\mathrm{CO}_{2}$ within the Atmospheric Boundary Layer}

The differences in potential temperature $\theta$ between the simulations are evident up to $1 \mathrm{~km}$ above the land surface during the daytime (Fig. 10a). Similarly, the differences in the specific humidity $q$ are clear up to $1 \mathrm{~km}$ above the ground (Fig. 10b). The vertical profiles of both $\theta$ and $q$ deviate more from the control in the cases of different rice-paddy areas than in the cases of different $\left[\mathrm{CO}_{2}\right]$. The clear difference of the vertical distribution of $\mathrm{CO}_{2}$ concentration $C$ among the simulations extends to even the upper regions of the atmosphere $(\approx 2 \mathrm{~km})$ (Fig. 10c). Note that the formation of a mixed layer in the area is influenced strongly by local advection, as supported by observations (Kuwagata et al. 1990; Kimura et al. 1997). Simulations without topography result in a typical vertical $\theta$ structure in a mixed layer (e.g., Stull 1988) (Online Supplement Fig. S1).

\subsection{Heat-Budget Analysis of the Atmospheric Boundary Layer}

The net heating of the atmospheric column $\left(Q_{n}\right)$ is low near the coastal plains, moderate in inland areas with extensive rice paddies, and particularly high at the bottom of the basin
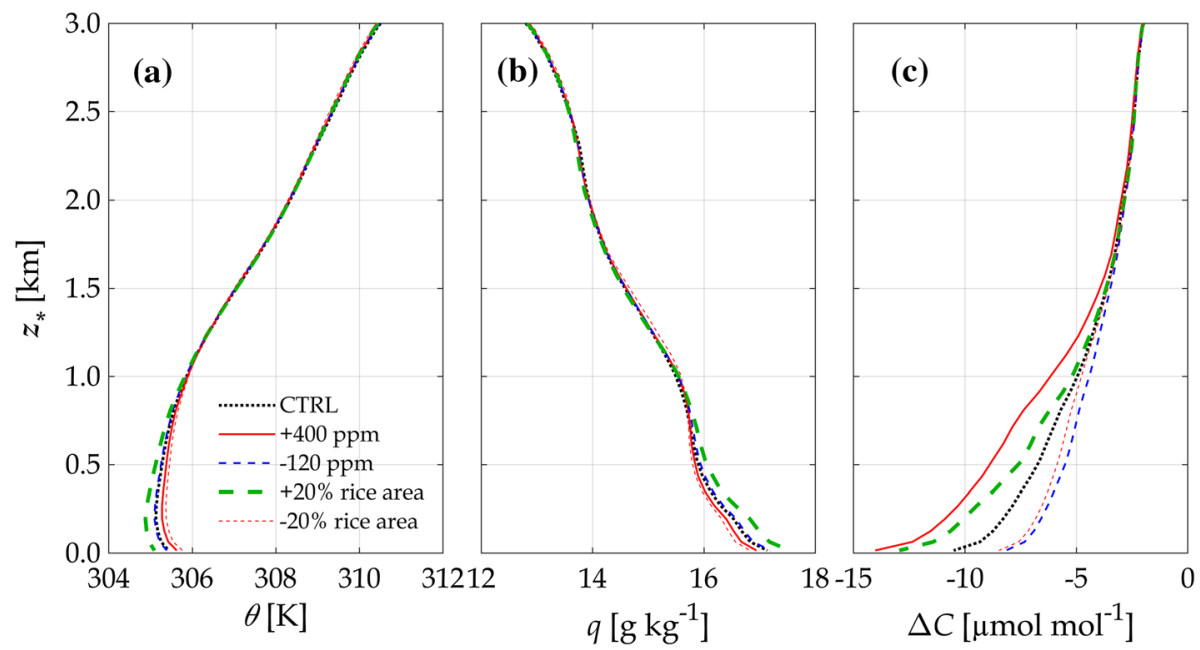

Fig. 10 Vertical distributions of simulated a potential air temperature $(\theta)$, b specific humidity $(q)$, and $\mathbf{c}$ deviation of atmospheric $\mathrm{CO}_{2}$ concentration from the background $(\Delta C)$ over the terrain normalized height $\left(z_{*}\right)$ at $1300 \mathrm{LT}$ averaged for rice-paddy areas (areal fraction $>0.5, n=301$ ) under control conditions (CTRL), increased or decreased background atmospheric $\mathrm{CO}_{2}$ concentration $\left(+400\right.$ or $\left.-120 \mu \mathrm{mol} \mathrm{mol}^{-1}\right)$, and increased or decreased rice-paddy areas $(+20 \%$ or $-20 \%)$ 


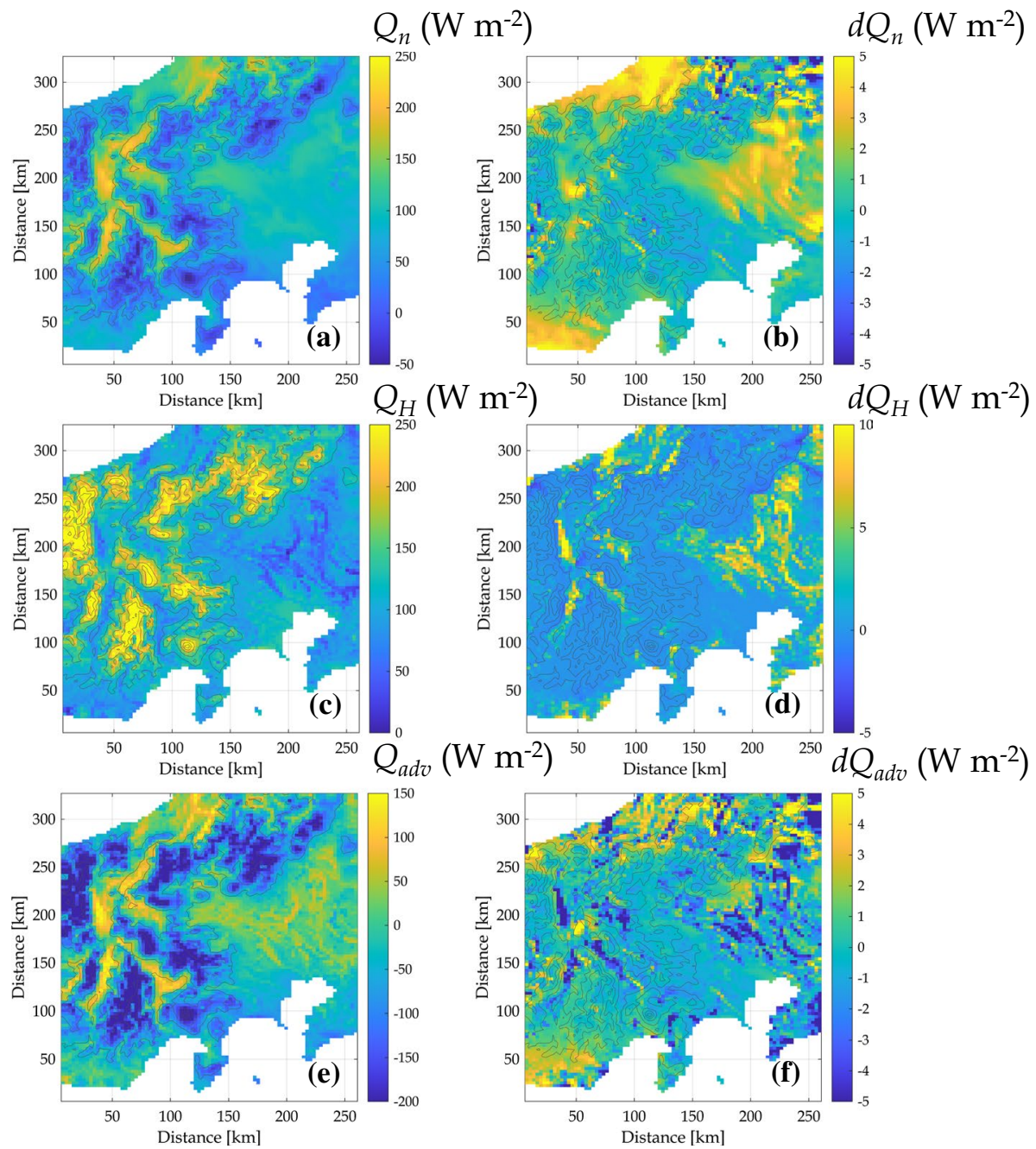

Fig. 11 Heat-budget analysis averaged over $10 \mathrm{~h}(0300-1300 \mathrm{LT})$. The net heating in the atmospheric column averaged over the $10 \mathrm{~h}\left(Q_{n}\right)$ is separated into the contributions from the sensible heat flux from the land surface $\left(Q_{H}\right)$ and advection $\left(Q_{a d v}\right)$ under control conditions (CTRL) (a, c, e). Their differences in simulations with increased background atmospheric $\mathrm{CO}_{2}$ concentration $\left(+400 \mu \mathrm{mol} \mathrm{mol}{ }^{-1}\right)$ compared with control conditions are also shown $(\mathbf{b}, \mathbf{d}, \mathbf{f})$. The contours indicate topography

(Fig. 11a). These results are consistent with the observations reported in Kuwagata et al. (1990). These spatial patterns of $Q_{n}$ are clearly governed by heating via advection, $Q_{a d v}$ (Fig. 11e).

Doubling $\left[\mathrm{CO}_{2}\right]$ increases $Q_{n}$ in most areas, particularly in the areas with extensive rice paddies because of the increased heating due to the surface sensible heat, $Q_{H}$ (Fig. $11 \mathrm{~b}, \mathrm{~d}$ ). Conversely, the magnitude of $Q_{a d v}$ in the areas with rice paddies tends to decrease, partially offsetting the effect of $Q_{H}$ (Fig. 11f). 


\section{Discussion}

\subsection{Reduced Heat-Mitigation Effect of Rice Paddies under Future $\mathrm{CO}_{2}$ Concentration}

The simulations show that doubling $\left[\mathrm{CO}_{2}\right]$ clearly increases the air temperature $T_{a}$ in both rice paddies and areas of other land-use types (Figs. 5 and 6). The clear difference in the value of $T_{a}$ between the different $\left[\mathrm{CO}_{2}\right]$ simulations near midday is attributed to the changes in the energy balance via the $\mathrm{CO}_{2}$ response of the stomatal conductance, $g_{s w}$ (Figs. 8 and 9). Our model simulations do not consider other factors that are sensitive to $\mathrm{CO}_{2}$, such as

\section{Sim2 - CTRL}
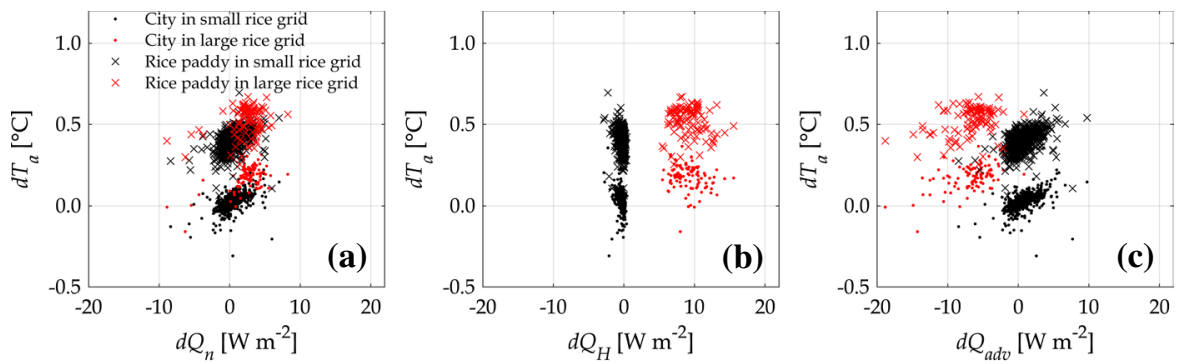

Sim2 - CTRL (without topography)
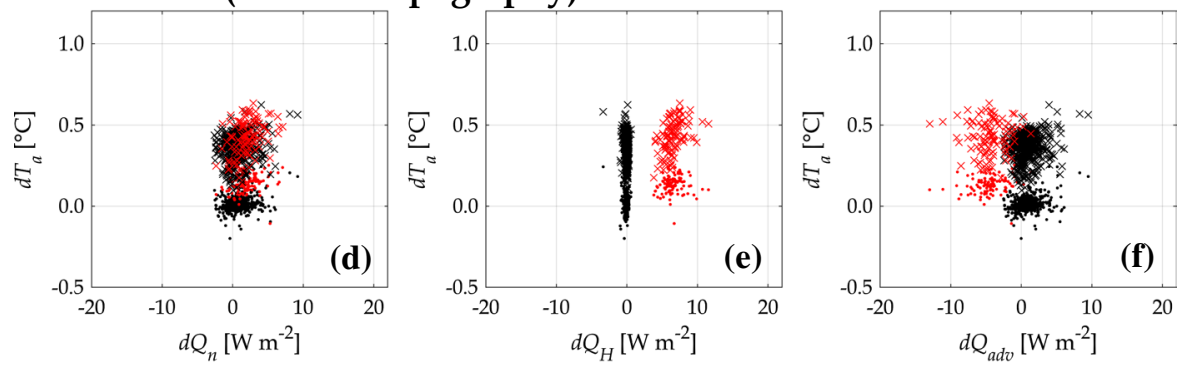

Sim5 - CTRL
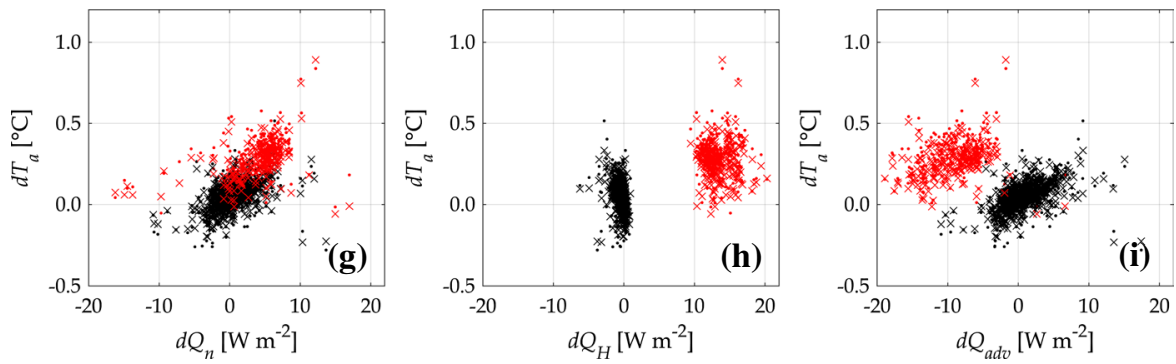

Fig. 12 The relationships between the differences in the components of the atmospheric heat budget $\left(Q_{n}\right.$, $Q_{H}$, and $\left.Q_{a d v}\right)$ and the differences in air temperature $1.5 \mathrm{~m}$ above the zero-plane displacement $\left(d T_{a}\right)$ in the cities and rice paddies between the simulations of the control (CTRL), doubling background atmospheric $\mathrm{CO}_{2}$ concentration (Sim2), and reducing the rice-paddy area by $20 \%$ (Sim5). Data are selected from the grid areas with a small rice-paddy areal fraction $(<1 \%, n=636)$ and a large rice-paddy areal fraction $(>60 \%, n=104)$ for panels a-f. For the comparisons between the control (CTRL) and Sim5 (g-i) simulations, data are selected from the grid areas with a small rice-paddy areal fraction $(<1 \%, n=760)$ and a large rice-paddy areal fraction $(>40 \%, n=216)$ based on the land-use map with reduced rice-paddy areal fraction 
the dynamic vegetation change in other land-use types (e.g., Notaro et al. 2007). Nonetheless, our results suggest that elevated $\left[\mathrm{CO}_{2}\right]$ increases air temperature in rice paddies at a greater rate than in other land uses that would be less sensitive to the $\left[\mathrm{CO}_{2}\right]$ change, such as city areas, provided that the atmospheric circulation pattern remains similar under elevated $\left[\mathrm{CO}_{2}\right]$.

The spatial variations of the $T_{a}$ change between the different simulations shown in Fig. 6 are influenced by the balance between the local heating and advection of the immediate atmospheric column (Fig. 12). During the daytime, the atmosphere above the areas dominated by rice paddies receives heat from the surrounding areas, resulting in a positive value of $Q_{a d v}$ (Fig. 11e), which is positively related to the areal coverage of rice paddy within each grid (Online Supplement Fig. S3). Under the elevated $\left[\mathrm{CO}_{2}\right]$ condition, the heat gradient between rice-paddy dominated areas and the surrounding areas decreases, resulting in the negative change in the magnitude of $Q_{a d v}$ (Figs. 11f and 12c, f). Despite reduced value of $Q_{a d v}$, the atmosphere above the rice-paddy dominated areas gains heat due to the intensified local heating $\left(Q_{H}\right)$ (Figs. $11 \mathrm{~d}$, and $12 \mathrm{~b}, \mathrm{e}$ ), resulting in a positive change in $T_{a}$ under elevated $\left[\mathrm{CO}_{2}\right]$ both in rice paddies and cities.

Most of the rice paddies and cities within the simulation domain experience a positive change in $T_{a}$ under elevated $\left[\mathrm{CO}_{2}\right](\mathrm{Fig} .6 \mathrm{a}, \mathrm{b})$, although there are many grid areas with a very small rice-paddy areal fraction of less than $1 \%$. While the increase in $T_{a}$ of both rice paddies and cities in the rice-paddy dominated areas is attributed to the local heating (i.e., $Q_{H}$ ), the positive change in $T_{a}$ in the areas with a small rice-paddy areal fraction is mainly attributed to the increase in $Q_{a d v}$ or reduced negative $Q_{a d v}$. These relationships between the changes of $T_{a}$ and heat-budget components are also observed in the simulation without topography (Fig. 12d-f).

The difference in $T_{a}$ between the simulations with different rice-paddy areas is also influenced by the changes in heat-budget components (Fig. 12g-i). Reducing rice-paddy areas increases the value of $Q_{H}$ and decreases the value of $Q_{a d v}$ in the rice-paddy dominated areas, and the net change in the atmospheric heat balance of $Q_{n}$ is positively related to the change in $T_{a}$. The systematic bias in the $T_{a}$ change between rice paddies and cities that is observed in the case of different $\left[\mathrm{CO}_{2}\right]$. (Fig. 12a-f) is not observed in the case of different areal fractions of rice paddies (Fig. $12 \mathrm{~g}-\mathrm{i}$ ) because the changes in energy balance of the land surface and resultant effects on the IBL structure are small in the case of different rice-paddy areas (Fig. 8). It is noteworthy that the changes in $T_{a}$ due to the change of rice-paddy areas vary considerably by location (Fig. 6c, d). The large spatial variation of the change in $T_{a}$ associated with the land-use change is likely related to the broad range of the change in the magnitude of $Q_{a d v}$ (Fig. 12i).

Within similar geographical conditions (e.g., the areal fraction of rice-paddy greater than 0.5 and altitude less than $100 \mathrm{~m}$ ), the spatial variations of the $T_{a}$ change in rice paddies also depend on the wind speed. The change in $T_{a}$ under elevated $\left[\mathrm{CO}_{2}\right]$ is clear in those grid squares with a moderate wind speed $U_{a}$ (Fig. 13), which is necessary to enhance atmosphere-land surface mixing (e.g., Ikawa et al. 2018), but a further increase in the wind speed enhances the local advection and dilutes the signal from the immediate land surface. This study assumes that land uses other than rice paddies are carbon neutral because our purpose is to isolate the $\mathrm{CO}_{2}$ effects of rice paddies on the atmosphere. This assumption enables us to use the value of $\Delta C_{a}$ as a tracer that tracks the influence of rice paddies on the atmosphere: the greater $\Delta C_{a}$, the greater the impact of rice paddies on the atmosphere.

Decreasing rice-paddy areas has a greater effect on air temperature over mixed land surfaces than do $\left[\mathrm{CO}_{2}\right]$ effects as indicated by $T_{a}$ in cities and also by the vertical distributions of potential temperature $\theta$ within the ABL (Figs. 6 and 10). Nevertheless, the change in $T_{a}$ 


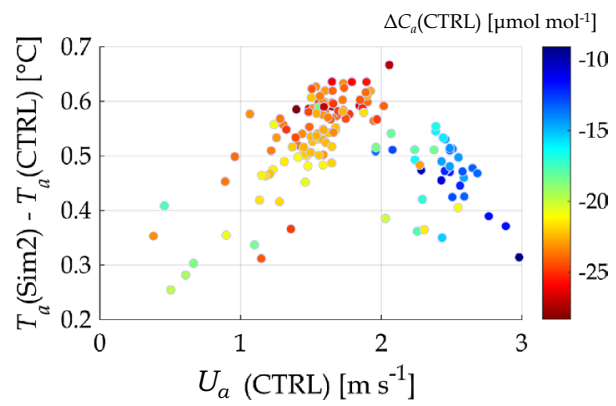

Fig. 13 Wind speed $\left(U_{a}\right)$ and difference of air temperature $1.5-\mathrm{m}$ above the zero-plane displacement $\left(T_{a}\right)$ over rice paddies in simulation 2 (background atmospheric $\mathrm{CO}_{2}$ concentration increased by $400 \mu \mathrm{mol} \mathrm{mol}{ }^{-1}$ ) compared with the control (CTRL) simulation at $1300 \mathrm{LT}$. The anomaly of atmospheric $\mathrm{CO}_{2}$ concentration from the background $\left(\Delta C_{a}\right)$ is also shown in colour. The data are only for altitudes below $100 \mathrm{~m}$ and the areal fractions of rice paddy greater than $0.5(n=151)$

in the cities (Fig. 6), the surface energy fluxes (Fig. 8), and the vertical distribution of $\theta$ (Fig. 10) among different $\left[\mathrm{CO}_{2}\right]$ conditions indicate that the effect of doubling $\left[\mathrm{CO}_{2}\right]$ still affects the air temperature and energy balance over the areas beyond the rice paddies. The $\left[\mathrm{CO}_{2}\right]$ effect on $\theta$ and $T$ is approximately half that of reducing the rice-paddy areas by $20 \%$, which is shown clearly in the grid-mean Bowen ratio (Fig. 8c). Additional model simulations indicate that the average magnitude of the changes in $T_{a}$ in cities caused by doubling $\left[\mathrm{CO}_{2}\right]$ is equivalent to a $10 \%$ decrease in the rice-paddy area within each grid square. We therefore argue that the impact of the physiological response to $\left[\mathrm{CO}_{2}\right]$ on the regional temperature is not negligible, at least in comparison to land-use change.

\subsection{Atmospheric Effects on Rice-Plant Temperature Mediated via Stomata}

Studies based on the FACE experiment have shown that the plant temperature increases via stomatal closure under elevated $\left[\mathrm{CO}_{2}\right]$, and that this increased temperature affects the rice grain quality, phenology (e.g., days to heading), and physiological processes (e.g., flowering time) (Usui et al. 2014; Zhang et al. 2015; Hasegawa et al. 2016; Kobayasi et al. 2019). Therefore, the question arises as to whether we need to consider an extra increase in plant temperature through the increase in atmospheric temperature via stomatal closure under elevated $\left[\mathrm{CO}_{2}\right]$.

We computed the canopy temperature, $T_{c}$ under elevated $\left[\mathrm{CO}_{2}\right]$ while keeping the other meteorological variables (i.e., $T_{a}, q_{a}$, and $\Delta C_{a}$ ) of the control simulation constant (Fig. 14a). This simulation yields the value of $T_{c}$ under elevated $\left[\mathrm{CO}_{2}\right]$ without considering the feedback from rice paddies to the atmosphere. The simulation results indicate that the feedback from rice paddies under doubled $\left[\mathrm{CO}_{2}\right]$ affects the value of $T_{c}$ by $0.19{ }^{\circ} \mathrm{C}$ at 1300 LT (Fig. 14b). The weaker sensitivity of $T_{c}$ compared with $T_{a}$ is attributed to the fact that an increased temperature tends to enhance the latent heat flux compared with the sensible heat flux, and the increase of $T_{a}\left(+0.44{ }^{\circ} \mathrm{C}\right)$ increases the value of $T_{c}$ by $0.28{ }^{\circ} \mathrm{C}$ if no humidity and $\mathrm{CO}_{2}$ feedbacks are considered (Online Supplement Fig. S4). Further consideration of the effects of decreased humidity and decreased the $\mathrm{CO}_{2}$ concentration $C$ due to enhanced photosynthesis result in a net increase in the value of $T_{c}$ by $0.19{ }^{\circ} \mathrm{C}$. 

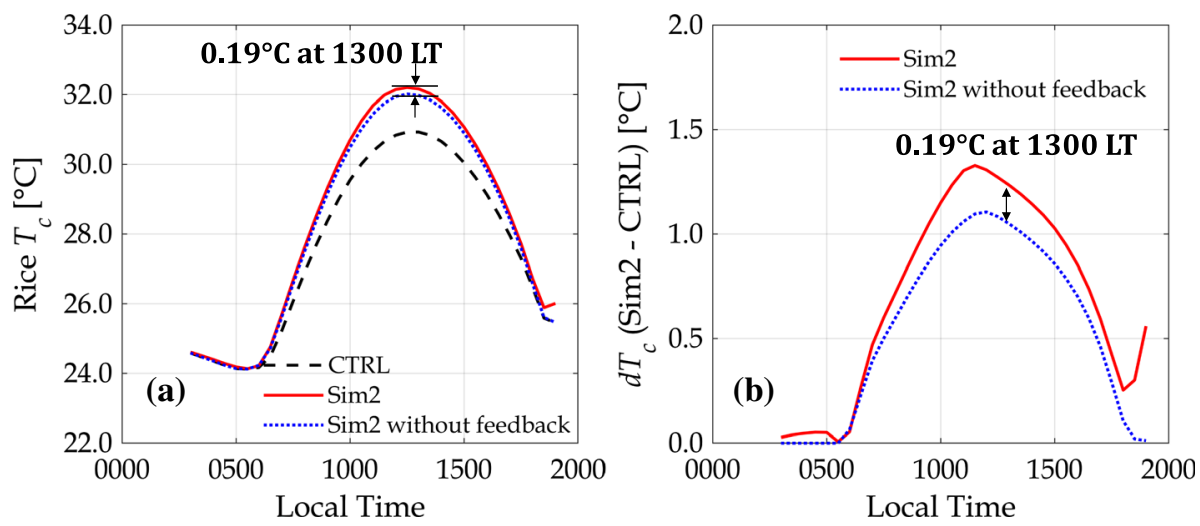

Fig. 14 a Simulated canopy temperature $\left(T_{c}\right)$ using average meteorological variables (air temperature, specific humidity, and anomaly of atmospheric $\mathrm{CO}_{2}$ concentration from the background) simulated under control conditions (CTRL), doubled background atmospheric $\mathrm{CO}_{2}$ concentration (simulation 2, 'Sim2'), and doubled background atmospheric $\mathrm{CO}_{2}$ concentration with other meteorological variables of CTRL ('Sim2 without feedback'). b Difference in $T_{c}$ between the simulations

The significance of the changes in $T_{c}$ due to the atmospheric change via stomatal closure may deserve further investigation. Rice grains are very sensitive to temperature, especially at the reproductive stage (Usui et al. 2016; Matsui and Hasegawa 2019). Moreover, temperature has a cumulative effect over the course of the rice-growing stage (Zhang and Tao 2013; Ishigooka et al. 2017), and even a small change in temperature may have a consequence in the developmental stage over time. Additionally, note that crops generally have periods in which they are particularly sensitive to temperature (e.g., germination, flowering, and ripening), and whether we should consider vegetation feedback to the atmosphere depends on the sensitivity of a particular phenological or physiological process to temperature (Combe et al. 2015).

\subsection{Limitations and Future Work}

This study is limited to typical summer conditions in Japan, when the effects of plant physiological processes on the atmosphere are the greatest. However, the ecophysiological properties of rice paddies change between the growing and non-growing seasons and also among different growth stages (Ono et al. 2013, 2015).

Although our aim in using a regional atmospheric model is to simulate the diurnal variations of meteorological variables as realistically as possible, we do not consider the air-land surface $\mathrm{CO}_{2}$ exchange in areas of land uses other than in rice paddies. This is because we are interested in isolating the effects of the $\mathrm{CO}_{2}$ responses of rice plants, and we assume that considering momentum, heat, and vapour fluxes would be sufficient to create the baseline structure of the ABL (Santanello et al. 2013). The complexity of $\mathrm{CO}_{2}$ fluxes in areas of other land-use types such as cities (Ueyama and Ando 2016) is also why we do not consider $\mathrm{CO}_{2}$-flux effects from other land-use types. Different simulations with topography conducted here do not result in a clear difference in velocity fields. However, changing the energy balance over extensive land-surface areas beyond rice-paddy areas may alter the patterns of atmospheric circulation. The changes in the atmospheric variables via different atmospheric flows under elevated $\left[\mathrm{CO}_{2}\right]$ is worth further investigation. 
The choice of the stomatal conductance model may be another factor in the uncertainty of the simulation results. The sensitivity of the stomatal conductance to $\mathrm{CO}_{2}$ is reduced by introducing the approximations of Medlyn et al. (2011). For example, the peak $d T_{c}$ value decreases by $0.3{ }^{\circ} \mathrm{C}$ in Fig. $14 \mathrm{~b}$ and the increase in atmospheric heating would be less. The difference is primarily attributed to the fact that Leuning-type models include the intercept $\Gamma$ for the $\mathrm{CO}_{2}$ effect, whereas the Medlyn model does not, at least in its original form. Further assessments of the stomatal conductance model are beyond the scope of this study. Because the increase in $T_{c}$ shown in Fig. 14 is reasonable compared with the results of the past rice FACE experiments (Yoshimoto et al. 2005; Sikma et al. 2020), we retain the current model for this study.

Regarding further realistic simulations, some other key aspects that can be considered to improve our model are an accurate temperature response and cloud formation. The effect of doubling $\left[\mathrm{CO}_{2}\right]$ on $T_{a}$ is conserved in both the rice paddies and cities under the simulations with a background air-temperature increase of $2{ }^{\circ} \mathrm{C}$ (average $T_{a}$ increases by $0.44{ }^{\circ} \mathrm{C}$ and $0.07{ }^{\circ} \mathrm{C}$, respectively, at $1300 \mathrm{LT}$ ). However, incorporating appropriate temperature functions in the model depends on further investigation on the temperature responses of ecophysiological properties of rice paddies. Cloud formation interplays with $\left[\mathrm{CO}_{2}\right]$ and affects the radiation budget. Decreased humidity under elevated $\left[\mathrm{CO}_{2}\right]$ may suppress ABL cloud formation and affect the radiation intensity (Vilà-Guerau de Arellano et al. 2012).

The good agreement between the simulated and observed diurnal patterns in air temperature in rice paddies and cities suggests that the coupled atmosphere and land-surface model presented herein may also be useful for investigating how land-use changes affect the regional climate (Fig. 3). Our results suggest that the effects of land-use change on the atmosphere vary considerably by location, and the spatial variation may be associated with the variation of the heat advection. Land-use changes may be assessed further based on real land-use change scenarios using land-use maps from different years and by effectively introducing the key land-surface processes of other types of land use (e.g., urban canopy, $\mathrm{CO}_{2}$ sequestration by forests) (Kusaka et al. 2001; Kusaka and Kimura 2004; Watanabe et al. 2004), depending on the research hypothesis to be tested.

\section{Conclusion}

A coupled atmosphere and crop energy-balance model is developed, and meteorological variables and energy balance near the land surface are simulated for past, current, and future $\left[\mathrm{CO}_{2}\right]$ and compared with cases involving different areal fractions of rice paddies. The model simulations show that doubling $\left[\mathrm{CO}_{2}\right]$ clearly increases the daily maximum air temperature in most of the areas when the air temperature is highest on a typical sunny day. Our model simulation also quantitatively evaluates the balance between the local heating and advection. The areas with a greater areal extent of rice paddies experience a net heating under elevated $\left[\mathrm{CO}_{2}\right]$, despite the negative change in advective heating received from the surrounding areas. Although the land-use change postulated herein has a greater impact than $\left[\mathrm{CO}_{2}\right]$ effects on the air temperature over larger spatial scales, the air temperature within the IBL (viz. $T_{a}$ ) over rice paddies is increased more by changing $\left[\mathrm{CO}_{2}\right]$ than by changing the rice-paddy areas. These results suggest an important interplay of plant physiological responses to $\mathrm{CO}_{2}$ on the heat-mitigation effects of rice paddies under a changing climate. 


\section{Appendix 1: Downwards shortwave and longwave radiation fluxes}

The shortwave flux $R_{s}\left(\mathrm{~W} \mathrm{~m}{ }^{-2}\right)$ is estimated using the following equation based on the methods summarized in Kondo et al. (1991)

$$
\begin{gathered}
R_{s}=R_{00}\left(\frac{d_{s}}{d_{0}}\right)^{2} f_{t} \cos \theta_{s} \\
\left(\frac{d_{s}}{d_{0}}\right)^{2}=1.00011+0.034221 \cos \eta+0.00128 \sin \eta+0.000719 \cos 2 \eta+0.000077 \sin 2 \eta
\end{gathered}
$$

Herein, $R_{00}$ is the solar constant $\left(1360 \mathrm{~W} \mathrm{~m}^{-2}\right), d_{s}$ is the distance between the Sun and Earth determined for each day of the year, $d_{0}$ is the average of $d_{s}, \theta_{s}$ is the solar zenith angle, and $\eta$ is the parameter corresponding to each day of the year. The fraction of the transmitted radiation $f_{t}$ is estimated as

$$
\begin{gathered}
f_{t}=\left(C_{1}+0.7 C_{2}\right)\left(1-C_{3}\right)\left(1+C_{4}\right), \\
C_{1}=0.21-0.2 \min \left\{\beta_{t}, 0.3\right\}, \\
C_{2}=10^{-\left(0.056+0.16 \beta_{t}^{1 / 2}\right) \frac{P\left(z_{* 1}\right)}{P_{0}} \sec \theta_{s},} \\
C_{3}=0.014\left(\frac{P\left(z_{* 1}\right)}{P_{0}} \sec \theta_{s}+7+2 \log _{10} w_{p}\right) \log _{10} w_{p}, \\
C_{4}=\left(0.0066+0.34 \sqrt{\beta_{t}}\right)\left(A_{S F C}-0.15\right),
\end{gathered}
$$

where $\beta_{t}$ is the turbidity of the atmosphere (dimensionless), $P$ is the atmospheric pressure $(\mathrm{kPa}), P_{0}$ is the atmospheric pressure at the sea level (assumed to be $100 \mathrm{kPa}$ in this study), and $A_{S F C}$ is the albedo of the land surface. The precipitable water $w_{p}(\mathrm{~cm})$ is estimated by vertically integrating the specific humidity $q$ over the calculation domain as

$$
w_{p}=10^{-4} \int_{0}^{z_{\infty}} q \rho_{0} \frac{h}{z_{T O P}} \mathrm{~d} z_{*},
$$

where $z_{\infty}$ is set to $10 \mathrm{~km}$; we assume that the specific humidity is zero at this height. The factor of $10^{-4}$ assumes that the density of water is $1000 \mathrm{~kg} \mathrm{~m}^{-3}$. Rearranging Eq. 17, we have

$$
\begin{gathered}
w_{p}=10^{-4} \int_{0}^{z_{T O P}} q \rho_{0 s} \Pi^{\left(c_{p} R^{-1}-1\right)} \frac{h}{z_{T O P}} \mathrm{~d} z_{*} \\
-10^{-4} \frac{P_{0}}{g}\left\{\left[q \Pi^{c_{p} R^{-1}}-\frac{q_{T O P}}{z_{\infty}-z_{T O P}} \frac{\Pi^{\left(c_{p} R^{-1}+1\right)} c_{p} \Theta}{\left(c_{p} R^{-1}+1\right) g}\right]_{\Pi\left(z_{T O P}\right)}^{\Pi\left(z_{\infty}\right)}\right\},
\end{gathered}
$$


where $\rho_{0 s}$ is the air density at the sea level $\left(\mathrm{kg} \mathrm{m}^{-3}\right)$ and $R$ is the gas constant of air $\left(\mathrm{J} \mathrm{kg}^{-1}\right.$ $\mathrm{K}^{-1}$ ).

The downwards longwave flux $R_{l d}\left(\mathrm{~W} \mathrm{~m}^{-2}\right)$ is fixed to $400 \mathrm{~W} \mathrm{~m}^{-2}$ because its diurnal variation is much smaller than that of $R_{s}$. In the simulation with an increased air temperature, the value of $R_{l d}$ under the increased air temperature $R_{l d+}$, is approximated as

$$
\begin{aligned}
& R_{l d+}=R_{l d}+4 \sigma \bar{T}^{3} d T, \\
& \bar{T} \approx \Theta\left(1-\frac{0.5 \bar{h} g}{c_{p} \Theta}\right),
\end{aligned}
$$

where $\sigma$ is the Stefan-Boltzmann constant, and $\bar{h}$ is the average atmospheric height over the calculation domain. The fraction of diffuse radiation $f_{d}$ used in the photosynthesis model is estimated based on Spitters et al. (1986) as follows

$$
\begin{gathered}
f_{d}=1 \quad\left(f_{t} \leq 0.22\right), \\
f_{d}=1-6.4\left(f_{t}-0.22\right)^{2} \quad\left(f_{t}>0.22, f_{t} \leq 0.35\right), \\
f_{d}=1.47-1.66 f_{t} \quad\left(f_{t} \geq 0.35\right),
\end{gathered}
$$

Supplementary Information The online version of this article (https://doi.org/10.1007/s10546-021-00604 -6)

Acknowledgements This work was supported by the Grant for Joint Research Program of the Institute of Low Temperature Science, Hokkaido University (20G019, 19G016, 18G015), by JSPS KAKENHI Grant Nos. 19H03077, 17H03896, and 20H03112, and by the Environment Research and Technology Development Fund (2-1907). We thank Enago (www.enago.jp) for the English language review. We thank two anonymous referees whose suggestions improved the model analysis. We also thank the editor whose comments improved the clarity of the manuscript. HI, TK, and WT contributed equally to this study; HI and TK conceived the idea; TK and HI developed the rice-crop model; TW developed the atmospheric model; and all authors contributed to discussion and writing.

Open Access This article is licensed under a Creative Commons Attribution 4.0 International License, which permits use, sharing, adaptation, distribution and reproduction in any medium or format, as long as you give appropriate credit to the original author(s) and the source, provide a link to the Creative Commons licence, and indicate if changes were made. The images or other third party material in this article are included in the article's Creative Commons licence, unless indicated otherwise in a credit line to the material. If material is not included in the article's Creative Commons licence and your intended use is not permitted by statutory regulation or exceeds the permitted use, you will need to obtain permission directly from the copyright holder. To view a copy of this licence, visit http://creativecommons.org/licenses/by/4.0/.

\section{References}

Avissar R, Pielke RA (1989) A parameterization of heterogeneous land surfaces for atmospheric numerical models and its impact on regional meteorology. Mon Weather Rev 117:2113-2136 
Bernacchi CJ, Portis AR, Nakano H, von Caemmerer S, Long SP (2002) Temperature response of mesophyll conductance. implications for the determination of rubisco enzyme kinetics and for limitations to photosynthesis in vivo. Plant Physiol 130:1992-1998

Chen F, Xu X, Barlage M, Rasmussen R, Shen S, Miao S, Zhou G (2018) Memory of irrigation effects on hydroclimate and its modeling challenge. Environ Res Lett 13:064009

Combe M, Vilà-Guerau de Arellano J, Ouwersloot HG, Jacobs CMJ, Peters W (2015) Two perspectives on the coupled carbon, water and energy exchange in the planetary boundary layer. Biogeosciences 12:103-123

de Pury DGG, Farquhar GD (1997) Simple scaling of photosynthesis from leaves to canopies without the errors of big-leaf models. Plant Cell Environ 20:537-557

Dong J, Xiao X, Zhang G, Menarguez MA, Choi CY, Qin Y, Luo P, Zhang Y, Moore B (2016) Northward expansion of paddy rice in northeastern Asia during 2000-2014. Geophys Res Lett 43:3754-3761

Du G, Liu W, Pan T, Yang H, Wang Q (2019) Cooling effect of paddy on land surface temperature in cold China based on MODIS data: a case study in Northern Sanjiang Plain. Sustainability 11:5672

Dyer AJ, Hicks BB (1970) Flux-gradient relationships in the constant flux layer. Q J R Meteorol Soc 96:715-721

Farquhar GD, von Caemmerer S, von Berry JA (1980) A biochemical model of photosynthetic $\mathrm{CO}_{2}$ assimilation in leaves of $\mathrm{C}_{3}$ species. Planta 149:78-90

Garratt JR (1994) The atmospheric boundary layer. Cambridge University Press, Cambridge

Hasegawa T, Sakai H, Tokida T et al (2016) Rice free-air carbon dioxide enrichment studies to improve assessment of climate change effects on rice agriculture. In: Hatfield JL, Fleisher D (eds) Advances in agricultural systems modeling. American Society of Agronomy, Crop Science Society of America, and Soil Science Society of America, Inc., pp 45-68

Hikosaka K, Anten NPR, Borjigidai A et al (2016) A meta-analysis of leaf nitrogen distribution within plant canopies. Ann Bot 118:239-247

Holmes RM (1970) Meso-Scale effects of agriculture and a large prairie lake on the atmospheric boundary layer. Agron J 62:546-549

Ikawa H, Ono K, Mano M, Kobayashi K, Takimoto T, Kuwagata T, Miyata A (2017) Evapotranspiration in a rice paddy field over 13 crop years. J Agric Meteorol 73:109-118

Ikawa H, Chen CP, Sikma M, Yoshimoto M, Sakai H, Tokida T, Usui Y, Nakamura H, Ono K, Maruyama A, Watanabe T (2018) Increasing canopy photosynthesis in rice can be achieved without a large increase in water use-A model based on free-air $\mathrm{CO}_{2}$ enrichment. Glob Change Biol 24:1321-1341

Ikawa H, Sakai H, Chen CP, Soong TH, Yonemura S, Taniguchi Y, Yoshimoto M, Tokida T, Zhang G, Kuwagata T, Nakamura H (2019) High mesophyll conductance in the high-yielding rice cultivar Takanari quantified with the combined gas exchange and chlorophyll fluorescence measurements under free-air $\mathrm{CO}_{2}$ enrichment. Plant Prod Sci 22:395-406

Ishigooka Y, Fukui S, Hasegawa T et al (2017) Large-scale evaluation of the effects of adaptation to climate change by shifting transplanting date on rice production and quality in Japan. J Agric Meteorol 73:156-173

Kimura F (1989) Heat flux on mixtures of different land-use surface: test of a new parameterization scheme. J Meteor Soc Jpn 67:401-409

Kimura F, Arakawa S (1983) A numerical experiment on the nocturnal low level jet over the Kanto Plain. J Meteorol Soc Jpn Ser II 61:848-861

Kimura F, Tanikawa R, Yoshizaki M (1997) Diurnal variation of precipitable water in clear days over the northern mountains in Kanto plain. Tenki 44:799-807

Kobayasi K, Eydi MJ, Sakai $\mathrm{H}$ et al (2019) Effects of free-air $\mathrm{CO}_{2}$ enrichment on heat-induced sterility and pollination in rice. Plant Prod Sci 22:374-381

Kondo J, Nakamura T, Yamazaki T (1991) Estimation of the solar radiation and downward atmospheric radiation. Tenki 38:41-48 (in Japanese)

Kondo J, Kanechika O, Yasuda N (1978) Heat and momentum transfers under strong stability in the atmospheric surface layer. J Atmos Sci 35:1012-1021

Kusaka H, Kimura F (2004) Coupling a single-layer urban canopy model with a simple atmospheric model: impact on urban heat island simulation for an idealized case. J Meteorol Soc Jpn 82:67-80

Kusaka H, Kondo H, Kikegawa Y, Kimura F (2001) A simple single-layer urban canopy model for atmospheric models: comparison with multi-layer and slab models. Bound-Layer Meteorol 101:329-335

Kuwagata T, Haginoya S, Ono K, Ishigooka Y, Miyata A (2018) Influence of local land cover on meteorological conditions in farmland: case study of a rice paddy field near Tsukuba City, Japan. J Agric Meteorol 74:140-153 
Kuwagata T, Ishigooka Y, Fukuoka M, Yoshimoto M, Hasegawa T, Usui Y, Sekiguchi T (2014) Temperature difference between meteorological station and nearby farmland—case study for Kumagaya City in Japan. SOLA 10:45-49

Kuwagata T, Kondo J, Sumioka M (1994) Thermal effect of the sea breeze on the structure of the boundary layer and the heat budget over land. Bound-Layer Meteorol 67:119-144

Kuwagata T, Sumioka M, Masuko N, Kondo J (1990) The daytime PBL heating process over complex terrain in central Japan under fair and calm weather conditions. I, Meso-scale circulation and the PBL heating rate. J Meteorol Soc Jpn 68:625-637

Leuning R (1995) A critical appraisal of a combined stomatal-photosynthesis model for $\mathrm{C}_{3}$ plants. Plant Cell Environ 18:339-355

Liu X, Chen F, Barlage M, Zhou G, Niyogi D (2016) Noah-MP-Crop: introducing dynamic crop growth in the Noah-MP land surface model. J Geophys Res Atmospheres 121:13953-13972

Maruyama A, Kuwagata T (2010) Coupling land surface and crop growth models to estimate the effects of changes in the growing season on energy balance and water use of rice paddies. Agric For Meteorol 150:919-930

Maruyama A, Nemoto M, Hamasaki T, Ishida S, Kuwagata T (2017) A water temperature simulation model for rice paddies with variable water depths. Water Resour Res 53:10065-10084

Masutomi Y, Ono K, Mano M, Maruyama A, Miyata A (2016) A land surface model combined with a crop growth model for paddy rice (MATCRO-Rice v. 1)-part 1: model description. Geosci Model Dev 9:4133-4154

Matsui T, Hasegawa T (2019) Effect of long anther dehiscence on seed set at high temperatures during flowering in rice (Oryza sativa L.). Sci Rep 9:1-8

Medlyn BE, Duursma RA, Eamus D, Ellsworth DS, Prentice IC, Barton CVM, Crous KY, Angelis PD, Freeman M, Wingate L (2011) Reconciling the optimal and empirical approaches to modelling stomatal conductance. Glob Change Biol 17:2134-2144

Mellor GL, Yamada T (1974) A hierarchy of turbulence closure models for planetary boundary layers. J Atmos Sci 31:1791-1806

Mellor GL, Yamada T (1982) Development of a turbulence closure model for geophysical fluid problems. Rev Geophys 20:851-875

Nocco MA, Smail RA, Kucharik CJ (2019) Observation of irrigation-induced climate change in the Midwest United States. Glob Change Biol 25:3472-3484

Notaro M, Vavrus S, Liu Z (2007) Global vegetation and climate change due to Future Increases in $\mathrm{CO}_{2}$ as projected by a fully coupled model with dynamic vegetation. J Clim 20:70-90

Ono K, Mano M, Han GH, Nagai H, Yamada T, Kobayashi Y, Miyata A, Inoue Y, Lal R (2015) Environmental controls on fallow carbon dioxide flux in a single-crop rice paddy, Japan. Land Degrad Dev 26:331-339

Ono K, Maruyama A, Kuwagata T, Mano M, Takimoto T, Hayashi K, Hasegawa T, Miyata A (2013) Canopy-scale relationships between stomatal conductance and photosynthesis in irrigated rice. Glob Change Biol 19:2209-2220

Oue H, Fukushima T, Maruyama T (1994) A micrometeorological function of paddy fields that control temperature conditions. J Jpn Soc Irrig Drain Rural Eng 62:955-960 (in Japanese)

Oue H (2005) Influences of meteorological and vegetational factors on the partitioning of the energy of a rice paddy field. Hydrol Process 19:1567-1583

Santanello JA, Peters-Lidard CD, Kennedy A, Kumar SV (2013) Diagnosing the nature of land-atmosphere coupling: a case study of dry/wet extremes in the U.S. Southern Great Plains. J Hydrometeorol $14: 3-24$

Sikma M, Ikawa H, Heusinkveld BG, Yoshimoto M, Hasegawa T, Groot Haar LT, Anten NPR, Nakamura H, Vilà-Guerau de Arellano J, Sakai H, Tokida T, Usui Y, Evers B (2020) Quantifying the feedback between rice architecture, physiology, and microclimate under current and future $\mathrm{CO}_{2}$ conditions. J Geophys Res Biogeosci 125:e2019JG005452

Spitters CJT, Toussaint HAJM, Goudriaan J (1986) Separating the diffuse and direct component of global radiation and its implications for modeling canopy photosynthesis Part II. Calculation of canopy photosynthesis. Agric For Meteorol 38:231-242

Stull R (1988) An introduction to boundary layer meteorology. Kluwer Academic Publishers, Dordrecht

Sun Y, Gu L, Dickinson RE, Norby RJ, Pallardy SG, Hoffman FM (2014) Impact of mesophyll diffusion on estimated global land $\mathrm{CO}_{2}$ fertilization. Proc Natl Acad Sci 111:15774-15779

Tatsumi K, Kuwabara Y, Motobayashi T (2019) Monthly variability in the photosynthetic capacities, leaf mass areas and leaf nitrogen contents of rice (Oryza sativa L.) plants and their correlations. J Agric Meteorol 75:111-119 
Ueyama M, Ando T (2016) Diurnal, weekly, seasonal, and spatial variabilities in carbon dioxide flux in different urban landscapes in Sakai, Japan. Atmos Chem Phys 16:14727-14740

Usui Y, Sakai H, Tokida T, Nakamura H, Nakagawa H, Hasegawa T (2014) Heat-tolerant rice cultivars retain grain appearance quality under free-air $\mathrm{CO}_{2}$ enrichment. Rice 7:6

Usui Y, Sakai H, Tokida T, Tokida T, Nakamura H, Nakagawa H, Hasegawa T (2016) Rice grain yield and quality responses to free-air $\mathrm{CO}_{2}$ enrichment combined with soil and water warming. Glob Change Biol 22:1256-1270

Vilà-Guerau de Arellano J, Ouwersloot HG, Baldocchi D, Jacobs CMJ (2014) Shallow cumulus rooted in photosynthesis. Geophys Res Lett 41:1796-1802

Vilà-Guerau de Arellano J, van Heerwaarden CC, Lelieveld J (2012) Modelled suppression of boundarylayer clouds by plants in a $\mathrm{CO}_{2}$-rich atmosphere. Nat Geosci 5:701-704

Wakiyama Y (2007) Moderation of summertime urban temperatures with proximity to agricultural land. J Agric Meteorol 63:81-88

Watanabe T (1994) Bulk parameterization for a vegetated surface and its application to a simulation of nocturnal drainage flow. Bound-Layer Meteorol 70:13-35

Watanabe T, Shimoyama K (2015) Atmosphere-land interaction (in Japanese). In: Institute of Low Temperature Science, Hokkaido University (ed) Handbook of Low Temperature Science. Maruzen, Tokyo, pp 239-258

Watanabe T, Yokozawa M, Emori S, Takata K, Sumida A, Hara T (2004) Developing a multilayered integrated numerical model of surface physics_-growing plants interaction (MINoSGI). Glob Change Biol 10:963-982

Yang Q, Huang X, Tang Q (2020) Irrigation cooling effect on land surface temperature across China based on satellite observations. Sci Total Environ 705:135984

Yoshida R, Iizumi T, Nishimori M, Yokozawa M (2012) Impacts of land-use changes on surface warming rates and rice yield in Shikoku, western Japan. Geophys Res Lett 39:L22401

Yoshimoto M, Oue H, Kobayashi K (2005) Energy balance and water use efficiency of rice canopies under free-air $\mathrm{CO}_{2}$ enrichment. Agric For Meteorol 133:226-246

Zhang G, Sakai H, Usui Y, Tokida T, Nakamura H, Zhu C, Fukuoka M, Kobayashi K, Hasegawa T (2015) Grain growth of different rice cultivars under elevated $\mathrm{CO}_{2}$ concentrations affects yield and quality. Field Crops Res 179:72-80

Zhang S, Tao F (2013) Modeling the response of rice phenology to climate change and variability in different climatic zones: comparisons of five models. Eur J Agron 45:165-176

Publisher's Note Springer Nature remains neutral with regard to jurisdictional claims in published maps and institutional affiliations.

\section{Authors and Affiliations}

\section{Hiroki lkawa ${ }^{1}$ (D) Tsuneo Kuwagata ${ }^{1}$ (D) . Shigenori Haginoya ${ }^{1,3}$. Yasushi Ishigooka $^{1} \cdot$ Keisuke Ono $^{1}$ D . Atsushi Maruyama ${ }^{1}$ (D) Hidemitsu Sakai ${ }^{1}$ (D) Minehiko Fukuoka ${ }^{1}$. Mayumi Yoshimoto ${ }^{1} \cdot$ Sachinobu Ishida ${ }^{4}$ (D) . Charles P. Chen ${ }^{5}$. Toshihiro Hasegawa ${ }^{6}$ D $\cdot$ Tsutomu Watanabe $^{2}$}

1 Institute for Agro-Environmental Sciences, National Agriculture and Food Research Organization, Tsukuba, Ibaraki 305-8604, Japan

2 Water and Material Cycles Division, Institute of Low Temperature Science, Hokkaido University, Sapporo, Hokkaido 060-0819, Japan

3 Meteorological Research Institute, Tsukuba, Ibaraki 305-0052, Japan

4 Graduate School of Science and Technology, Hirosaki University, Hirosaki, Aomori 036-8561, Japan

5 Department of Biology and Chemistry, Azusa Pacific University, Azusa, California 91702, USA

6 Tohoku Agricultural Research Center, National Agriculture and Food Research Organization, Morioka, Iwate 020-0198, Japan 